\title{
Structural transformations and adsorption properties of PtNi nanoalloy thin film electrocatalysts prepared by magnetron co-sputtering
}

\author{
Olaf Brummel $^{\mathbf{a}^{*}}$, Fabian Waidhas ${ }^{\mathrm{a}}$, Ivan Khalakhan ${ }^{\mathbf{b}}$, Mykhailo Vorokhta $^{\mathrm{b}}$, Martin. Dubau ${ }^{\mathrm{b}}$, \\ Gábor Kovács $^{\mathbf{c}}$, Hristiyan A. Aleksandrov ${ }^{\mathbf{c}, \mathbf{d}}$, Konstantin M. Neyman ${ }^{\mathbf{c}, \mathbf{e}}$, Vladimir Matolín ${ }^{\mathbf{b}}$, Jörg Libuda $^{\mathbf{a}, \mathbf{f}}$ \\ ${ }^{a}$ Lehrstuhl für Physikalische Chemie II, Friedrich-Alexander-Universität Erlangen-Nürnberg, Egerlandstrasse 3, \\ 91058 Erlangen, Germany \\ ${ }^{b}$ Charles University, Faculty of Mathematics and Physics, Department of Surface and Plasma Science, $V$ \\ Holešovičkách 2, 18000 Prague, Czech Republic \\ cDepartament de Ciència dels Materials i Química Física and Institut de Química Teòrica i Computacional, \\ Universitat de Barcelona, C/Martí i Franquès 1, 08028 Barcelona, Spain \\ ${ }^{d}$ Faculty of Chemistry and Pharmacy, University of Sofia, 1126 Sofia, Bulgaria \\ ICREA (Institució Catalana de Recerca i Estudis Avançats), Pg. Lluís Companys 23, 08010 Barcelona, Spain \\ ${ }^{f}$ Erlangen Catalysis Resource Center, Friedrich-Alexander-Universität Erlangen-Nürnberg, Egerlandstrasse 3, \\ 91058 Erlangen, Germany
}

\begin{abstract}
PtNi thin film catalysts provide both higher activity and enhanced Pt efficiency in the oxygen reduction reaction (ORR) in comparison to pure Pt catalysts. In order to explore the structural transformations and degradation mechanisms in such films, we combine studies by cyclic voltammetry $(\mathrm{CV})$, electrochemical atomic force microscopy (EC-AFM), and electrochemical infrared reflection absorption spectroscopy (EC-IRRAS) using $\mathrm{CO}$ as a probe molecule. The PtNi model thin film catalysts were prepared by magnetron sputtering on carbon coated Au targets or freshly cleaved highly ordered pyrolytic graphite (HOPG) and characterized by scanning electron microscopy (SEM), energy dispersive X-ray spectroscopy (EDX) and X-ray photoelectron spectroscopy (XPS). Subsequently, structural changes of the film and changes of the CO adsorption properties were followed by EC-IRRAS as a function of the applied potential.

All results were compared to reference experiments on $\operatorname{Pt}(111)$ performed under identical conditions. For $\operatorname{Pt}(111)$, well-ordered (111) facets are stable upon potential cycling up to 1.2 of the
\end{abstract}


voltage of the reversible hydrogen electrode $\left(\mathrm{V}_{\mathrm{RHE}}\right)$. At higher potential, surface roughening initially leads to the formation of [110] and [100] steps whereas [110] steps are the most dominant defect structure at potentials above $1.3 \mathrm{~V}_{\mathrm{RHE}}$. The roughening transition gives rise to characteristic changes in IR spectrum of adsorbed CO.

The sputtered PtNi catalyst film shows a weak decrease in grain size upon potential cycling up to 1.1 $\mathrm{V}_{\mathrm{RHE}}$. Freshly prepared PtNi catalysts show two characteristic IR bands in the on-top CO region. The signal at lower wavenumbers is assigned to isolated $\mathrm{CO}$ on $\mathrm{Pt}$ sites. Based on calculations using density functional theory (DFT) modeling we suggest that another peculiar blue-shifted CO band can be attributed to dicarbonyls on low-coordinated Pt centers, which are generated by the leaching of surface Ni. The blue-shifted band decreases upon cycling to higher potential and vanishes at $1.1 \mathrm{~V}_{\mathrm{RHE}}$ as a result of the increasing Pt mobility. A dramatic change of the film structure is observed upon potential cycling to $1.2 \mathrm{~V}_{\mathrm{RHE}}$. CV indicates the formation of [110] and [100] steps and AFM points out a strong decrease in particle size. EC-IRRAS shows the appearance of a new $\mathrm{CO}$ band that is broadened and red-shifted by more than $20 \mathrm{~cm}^{-1}$. Based on calculated DFT data, we assign these changes to a transient enrichment of $\mathrm{Ni}$ in the surface or subsurface region upon dissolution of Pt. Upon cycling to even higher potential (up to $1.5 \mathrm{~V}_{\mathrm{RHE}}$ ), $\mathrm{Ni}$ is completely leached from the film, and large Pt particles are formed by ripening and/or agglomeration, which again show the characteristic CV and CO IR spectra of rough polycrystalline Pt.

Keywords: platinum, nickel, oxygen reduction reaction, electrochemical infrared spectroscopy, electrochemical atomic force microscopy, cyclic voltammetry, density functional theory *corresponding author: olaf.brummel@fau.de

\section{Introduction}

Fuel cells are a key technology for the storage and conversion of renewable energies. ${ }^{[1]}$ One of the main challenges in fuel cell development is the improvement of the energy conversion efficiency. To reach high energy conversion efficiency at medium and low power levels, it is necessary to improve the activity of the cathode catalyst beyond the state of the art of current $\mathrm{Pt} / \mathrm{C}$ catalysts. ${ }^{[2]}$ One strategy to reach this aim is the use of Pt alloy catalysts. For instance, PtNi catalysts show considerably enhanced activity for the oxygen reduction reaction (ORR) in comparison to pure 
$\mathrm{Pt}^{[3]}$ Stamenkovic et al. showed that $\mathrm{Pt}_{3} \mathrm{Ni}(111)$ can be ten times more active than $\mathrm{Pt}(111)$ and 90 times more active than $\mathrm{Pt} / \mathrm{C}$ catalysts for polymer electrolyte membrane fuel cells (PEMFCs). ${ }^{[3 a]}$ Since metallic $\mathrm{Ni}$ is not stable under ORR conditions, ${ }^{[4]}$ the surface of such catalysts is $\mathrm{Ni}$ free and $\mathrm{Ni}$ can be present in subsurface layers only. ${ }^{[2 b, 3 a, 5]} \mathrm{Here}, \mathrm{Ni}$ can have an electronic effect on surface $\mathrm{Pt}$, lowering slightly the binding energy of the adsorbed intermediates $\left(\mathrm{O}^{*}, \mathrm{HO}^{*}\right.$ and $\left.\mathrm{HOO}^{*}\right)$ and, thus, improving the ORR activity. ${ }^{[3 a, 6]}$ In bimetallic catalysts, however, the geometric structure also differs from that of the parent metal. ${ }^{[7]}$ Such geometric or strain effects can also modify the binding energy of intermediates, ${ }^{[6 b, 8]}$ and electronic, geometric and strain effects are often closely interrelated.

To improve the applicability of fuel cell technology, long time stability is essential. ${ }^{[9]}$ Typically, structural changes of the catalyst under operation conditions determine the lifetime of a fuel cell. In the case of Pt-alloy catalyst various degradation mechanisms are considered, such as $\mathrm{Pt}$ dissolution, Ostwald ripening, particle agglomeration, corrosion of the support, particle detachment, and leaching of alloying metal atoms. ${ }^{[2 a]}$ Mayrhofer et al. showed that Pt dissolution in acidic media takes place above $1.1 \mathrm{~V}_{\mathrm{RHE}}$ (voltage of the reversible hydrogen electrode) under dynamic conditions, i.e. it is more pronounced during potential cycling as compared to steady state conditions. ${ }^{[10]}$ Here, $\mathrm{Pt}$ dissolution takes place both in the positive and the negative scan direction, however, dissolution in negative scan directions is more pronounced. ${ }^{[10-11]}$ Several groups investigated the degradation of Pt nanoparticles under ORR conditions and observed loss of the active surface area during the operation which is attributed to dissolution and redeposition of $\mathrm{Pt}$ on larger particles so called Ostwald repining. ${ }^{[12]}$ Also Pt dissolution and redeposition in the ionomer phase was observed. ${ }^{[12]}$ Finally, Pt particles that come in contact can agglomerate and form a larger particle which also reduces the active surface area. Corrosion of the carbon support ${ }^{[13]}$ and particle detachment ${ }^{[13 a]}$ can accelerate this agglomeration process. Whereas achieving the stability is already a great challenge for monometallic catalyst particles, the situation becomes even more complex in the case of alloys. Even if the surface is protected by a Pt layer, bulk atoms may leach out by segregation to the surface ${ }^{[14]}$, through defects of the protective Pt layer, ${ }^{[15]}$ or upon dissolution of surface Pt. ${ }^{[2 a, 10]}$

To understand the changes in the activity for a given catalytic material, it is essential to explore these complex structural transformations under reaction conditions. In this work, we investigate 
the behavior of nanostructured alloy electrocatalysts films prepared by radio-frequency (rf)magnetron co-sputtering. ${ }^{[16]}$ The latter method provides a promising alternative for the preparation of high-surface-area catalytic coating, in comparison to the more common wet chemical preparation techniques. Rf-magnetron sputtering is suitable for coating both large electrode areas and small electrodes of microfluidic power generation devices. Previously, we prepared bimetallic PtCo films by rf-magnetron co-sputtering ${ }^{[17]}$ which showed high activity as ORR catalysts in fuel cell tests. ${ }^{[17 c]}$ In this work, we investigate the structural transformation of PtNi nanoalloy catalysts under dynamic operation conditions at potentials up to $1.5 \mathrm{~V}_{\mathrm{RHE}}$, which may occur during startup/shutdown of the cell. $\left.{ }^{[10,} 17 \mathrm{a}, 18\right]$ Whereas EC-AFM provides information on the morphological changes in the catalyst film, we use EC-IRRAS to probe the nature of the local active sites at the surface of the alloy particles.

\section{Experimental Section and Theoretical Methods}

\subsection{Sample and Equipment Preparation}

Equipment: All glass and Teflon equipment was cleaned in a solution of NOCHROMIX® (SigmaAldrich) and concentrated sulfuric acid (Merck, emsure, $98 \%$ ) overnight and rinsed several times with ultra-pure water (MilliQ Synergy UV, $18.2 \mathrm{M} \Omega \mathrm{cm}$ at $25^{\circ} \mathrm{C}$, TOC $<5 \mathrm{ppm}$ ). Subsequently, the equipment was boiled in ultra-pure water at least 3 times. As electrolyte, we used a solution of $0.1 \mathrm{M} \mathrm{HClO}_{4}\left(\right.$ Merck, suprapur, $70 \%$ ) or, respectively, $0.1 \mathrm{M} \mathrm{H}_{2} \mathrm{SO}_{4}$ (Merck, suprapur, 96\%) in ultrapure water and degassed the solution at least for $20 \mathrm{~min}$ with Ar (Linde, 6.0) before measurement.

PtNi thin film catalysts: All PtNi catalysts were prepared by non-reactive magnetron co-sputtering. The catalysts for the IR spectroscopy and CV experiments were prepared on polished Au targets. A polycrystalline Au bead-type electrode was used for cyclic voltammetry. This electrode was produced by melting a $0.5 \mathrm{~mm} \mathrm{Au}$ wire in the flame of a Bunsen burner to form a bead. Subsequently, one side of the latter was rasped and polished to form a shiny surface with an area of $5.3 \mathrm{~mm}^{2}$. Before preparation of the catalyst film, we tested the Au electrode by cyclic voltammetry in $0.1 \mathrm{M} \mathrm{HClO}_{4}$. For IR spectroscopy, we used a polished Au target (Safina 99.99\%) with a surface area of $110 \mathrm{~mm}^{2}$. On these targets, we deposited first a protective carbon buffer layer $20 \mathrm{~nm}$ thick to prevent alloy formation of our catalyst with the Au substrate. The carbon was 
deposited in a commercial high-vacuum system MED020 (Baltec) equipped with a magnetron. A graphite target (Goodfellow, purity of 99.997\%) with a diameter of 2 in. was used at a distance of $50 \mathrm{~mm}$ from the substrate and a dc power of $10 \mathrm{~W}$ was applied in Ar atmosphere with a total pressure of $8 \times 10^{-1} \mathrm{~Pa}$. The catalyst for the AFM measurements was prepared directly on a freshly cleaved highly ordered pyrolytic graphite (HOPG) substrate. The PtNi thin films were prepared by sputtering simultaneously Pt and Ni using a TORUS 2 source in a UHV magnetron (Kurt Lesker) and an additional home-built dc magnetron in Ar atmosphere with a pressure of $6 \times 10^{-1} \mathrm{~Pa}$. For Platinum deposition, we used a 2 in. Pt target (Safina, 99.99\%) at a distance of $200 \mathrm{~mm}$ to the substrates and applied a power of $20 \mathrm{~W}$. Nickel was deposited using a 2 in. Ni target (Kurt Lesker, $99.99 \%$ ) at a distance of $90 \mathrm{~mm}$ to the surface and an applied power of $25 \mathrm{~W}(13.56 \mathrm{MHz})$. The two magnetrons are positioned in an angle of $45^{\circ}$ to each other. Before deposition the preparation chamber was evacuated up to $2 \times 10^{-4} \mathrm{~Pa}$. The grow rate of the PtNi thin film was $3.3 \mathrm{~nm} \mathrm{~min}{ }^{-1}$. After preparation, the samples were characterized using XPS, SEM, and EDX. SEM images were acquired with a Mira 3 microscope (Tescan) and EDX spectra were taken with an additional EDX detector (Bruker, XFlash) in the microscope.

Single crystal preparation: The $\operatorname{Pt}(111)$ single crystals were prepared by flame annealing. For cyclic voltammetry, a bead-type single crystal electrode was used with a surface area of $4.5 \mathrm{~mm}^{2}$ (icryst, depth of roughness $<0.05 \mathrm{~mm}$, accuracy of orientation $<0.5^{\circ}$ ) and for in-situ IR spectroscopy a larger $\operatorname{Pt}(111)$ single crystal was used with a surface area of $78.5 \mathrm{~mm}^{2}$ (MaTeck, $\left.99,999 \%,<0.01 \mu \mathrm{m},<0.4^{\circ}\right)$. For preparation, the $\operatorname{Pt}(111)$ single crystals were annealed for two minutes in the flame of a Bunsen burner and cooled down to RT in an atmosphere of Ar (Linde, 6.0) and $\mathrm{H}_{2}$ (Linde 5.0) in a ratio of ca. 3:1. We transferred the electrodes into the measuring cells using a droplet of degassed ultrapure water. A detailed description of the preparation method is given in literature. ${ }^{[19]}$ The thin film PtNi samples were used without further precleaning.

\subsection{Experimental Techniques}

Cyclic voltammetry: Cyclic voltammetry was measured in $0.1 \mathrm{M} \mathrm{HClO}_{4}$ (Merck, suprapur, $70 \%$ ) with a three-electrode setup in a home-built cell. The measurements were performed in the socalled hanging meniscus configuration using bead-type electrodes as working electrodes (WE). ${ }^{[19 b]}$ A gold wire was used as counter electrode (CE) and a RHE as reference electrode (RE). A 
commercial potentiostat (Gamry, Reference 600) was used and during the whole measuring procedure the potential was controlled. We recorded all cyclic voltammograms with a scan-rate of $50 \mathrm{mV} \mathrm{s}^{-1}$. A detailed description of the measuring procedure applied is provided in Section 3.1.

In-situ atomic force microscopy: Electrochemical AFM measurements were performed in $0.1 \mathrm{M}$ $\mathrm{H}_{2} \mathrm{SO}_{4}$ using a commercial AFM (Bruker, Multimode 8) equipped with the electrochemistry extension including a $50 \mu \mathrm{L}$ electrochemical liquid cell mounted on the sample. A three electrode setup was used with a $\mathrm{Pt}$ wire (Safina, 99.99\%) as $\mathrm{CE}$ and a miniature leak-free $\mathrm{Ag} / \mathrm{AgCl}$ (Innovative Instruments, Inc. 3.4M KCl, 0.205 , $\mathrm{V}_{\mathrm{NHE}}$ ) RE. To ensure comparability of the results, all measured potentials in this work are given with reference to the RHE. Cycling was performed with the internal potentiostat of the AFM using the procedure and parameters described in Section3.1. After each cycling step, the procedure was stopped and AFM images were recorded.

In-situ IR spectroscopy: All electrochemical IR spectra were measured in $0.1 \mathrm{M} \mathrm{HClO}_{4}$ (Merck, suprapur, $70 \%$ ) with a Fourier transform infrared (FTIR) spectrometer with evacuated optics (Bruker Vertex 80v) in external reflection mode and a liquid nitrogen cooled mercury cadmium telluride (MCT) detector. We used an optics adaptation for electrochemical measurements (Bruker) with a home-built Teflon cell. $\mathrm{A} \mathrm{CaF}_{2}$ hemisphere (Korth) was used as an IR transparent window material. All potentials were controlled using a commercial potentiostat (Gamry Reference 600), a gold wire as CE, and a RHE as RE. We recorded 128 scans per spectrum with a resolution of 2 $\mathrm{cm}^{-1}$. The acquisition time per spectrum was $57 \mathrm{~s}$. CO (Linde 4.7) was adsorbed for $4 \mathrm{~min}$ at 0.05 $\mathrm{V}_{\mathrm{RHE}}$ and all reference spectra were taken at this potential. For more experimental details see Section 3.1.

\subsection{Computational Details}

Electronic structure calculations based on DFT were carried out using the periodic plane-wave code VASP ${ }^{[20]}$ with the Perdew-Wang (PW91) ${ }^{[21]}$ implementation of the generalized gradient approximation (GGA) for the exchange-correlation functional. A plane-wave basis set with a 415 $\mathrm{eV}$ cut-off for the kinetic energy and the projector-augmented wave description of core-valence electron interactions were employed. ${ }^{[22]}$ The one-electron Kohn-Sham states were smeared by 0.1 $\mathrm{eV}$ using the first-order method of Methfessel and Paxton; ${ }^{[23]}$ finally, converged energies were 
extrapolated to the zero smearing. The relaxation of all atoms in the studied models (if not stated otherwise) was performed during the geometry optimization until forces acting on each atom became lower than $0.2 \mathrm{eV} / \mathrm{nm}$. The reported $\mathrm{CO}$ adsorption energies have been calculated with respect to the energies of $\mathrm{Pt}_{\mathrm{n}}$ or $\mathrm{Pt}_{\mathrm{n}} \mathrm{Ni}_{\mathrm{m}}$ models and a free $\mathrm{CO}$ molecule, defined in such way that negative values correspond to exothermic adsorption. No corrections for the zero-point energies have been applied. The stretching frequency of the adsorbed $\mathrm{CO}$ molecules $\omega(\mathrm{C}-\mathrm{O})$ was calculated numerically, in a harmonic approximation via consecutive displacements of $\mathrm{C}$ and $\mathrm{O}$ atoms by $3 \mathrm{pm}$ in three Cartesian directions. In the case of multiple $\mathrm{CO}$ adsorbates, the dynamic coupling between $\mathrm{CO}$ molecules was taken into account by including the vibration of all $\mathrm{CO}$ molecules in one calculation. Our tests demonstrated that the inclusion of displacements of the Pt atom on-top of which the $\mathrm{CO}$ molecule is adsorbed in the $\mathrm{C}-\mathrm{O}$ frequency calculation shifts frequency values by less than $1 \mathrm{~cm}^{-1}$. The calculated $\mathrm{CO}$ stretching frequency values were corrected with respect to the gas phase experimental value $v(\mathrm{C}-\mathrm{O})=\omega(\mathrm{C}-\mathrm{O})+14 \mathrm{~cm}^{-1}$ and only these corrected frequency values $v(\mathrm{C}-\mathrm{O})$ are discussed in this work.

All calculations of nanoparticle models of 79 and 140 atoms with well-defined (111) and (100) facets were carried out at the $\Gamma$-point in the reciprocal space. The minimal separation between particles in adjacent supercells was always higher than $0.7 \mathrm{~nm}$, at which the interaction between metal NPs was found to be negligible. ${ }^{[24]} \mathrm{Pt}(111)$ surface was modeled as a four-layer slab with a $(3 \times 3)$ surface unit cell, repeated in a supercell geometry with a vacuum spacing of at least $1 \mathrm{~nm}$ between the slabs. The Brillouin zone was sampled by a Monkhorst-Pack mesh ${ }^{[25]}$ of $5 \times 5 \times 1$ k-points. The $\mathrm{CO}$ adsorbates were bound to one side of the slabs, and were allowed to relax during geometry optimizations together with metal atoms of the two adjacent layers. The two other slab layers were kept fixed at the calculated bulk-terminated geometry with Pt-Pt distances of $272 \mathrm{pm}$.

\section{Results and Discussion}

\subsection{Sample Preparation and Experimental Procedure}

We investigated structural transformations, adsorption properties and the stability of PtNi catalysts with a Pt:Ni ratio of 1:1. All measurements were performed at a pH 1 in $0.1 \mathrm{M} \mathrm{HClO}_{4} \mathrm{Or} \mathrm{H}_{2} \mathrm{SO}_{4}$, to mimic the acidic environment in PEMFCs. The experiments were performed in a way that the comparability is achieved to the best possible level for the different in-situ methods used, namely 
$\mathrm{CV}$, EC-AFM and EC-IRRAS. Whenever it is reasonable, we compare our results with data of reference measurements performed under identical conditions using an ideal $\operatorname{Pt}(111)$ electrode. Additionally, we performed extensive DFT calculations to rationalize the in-situ IR data.

In Figure 1 we illustrate the experimental procedure applied in case of the EC-IRRAS experiments. The measurement procedure consists of three steps, (1) sample preparation, (2) measurement, and (3) potential cycling. Step (2) and (3) were repeated several times, while the upper potential limit during potential cycling was increased by $100 \mathrm{mV}$ per cycle, starting at $0.9 \mathrm{~V}_{\mathrm{RHE}}$ and ending at 1.5

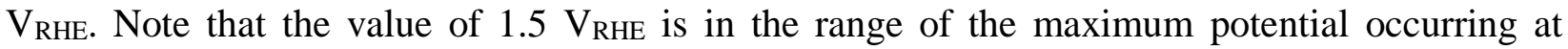
startup/shutdown of fuel cells. ${ }^{[10,17 a, 18]}$ Except for the first treatment ( 0.05 to $0.9 \mathrm{~V}_{\mathrm{RHE}}, 5$ cycles, $\left.50 \mathrm{mV} \cdot \mathrm{s}^{-1}\right), 10$ repetitions were applied per potential cycling treatment ( 0.05 to 1.0 to $1.5 \mathrm{~V}_{\mathrm{RHE}}, 10$ cycles, $\left.200 \mathrm{mV} \cdot \mathrm{s}^{-1}\right)$.

The potential cycling treatments were followed by CV, EC-AFM and EC-IRRAS measurements. The experimental procedure for the case EC-IRRAS is shown in Figure 1b. Briefly, the sample was saturated with $\mathrm{CO}$ at $0.05 \mathrm{~V}_{\mathrm{RHE}}$, the electrolyte was purged and, subsequently, IR spectra were recorded in thin film configuration at potentials between 0.05 and $0.9 \mathrm{~V}_{\mathrm{RHE}}$, (reference at 0.05 $\mathrm{V}_{\mathrm{RHE}}$ ). For further details, we refer to the Experimental Section 2.2.

For the AFM measurements, we prepared PtNi films on freshly cleaved HOPG, which we already used successfully for in-situ AFM measurements in a previous work. ${ }^{[17 \mathrm{a}]}$ For EC-IRRAS, however, a highly reflective metallic substrate is advantageous to obtain good signal/noise ratios. Therefore, we used a polished Au substrate instead which was covered by a $20 \mathrm{~nm}$ carbon layer by magnetron sputtering (see Section 2.1). The layer mimics the carbon support in a fuel cell, prevents alloy formation of the NiPt layer with the underlying Au substrate, and it is sufficiently transparent to preserve the IR reflectivity of the Au substrate. ${ }^{[26]}$ To ensure the comparability of the results, we used the same substrate for CV. Instead of the large Au samples for EC-IRRAS, here we used a polycrystalline Au bead-type electrode, however, on which we deposited a carbon layer. This enabled us to measure CVs for both the PtNi catalyst and the $\mathrm{Pt}(111)$ reference in hanging meniscus configuration. ${ }^{[19 b]}$

On all supports described above, a $10 \mathrm{~nm}$ PtNi thin film was deposited by magnetron co-sputtering. After preparation, the films were characterized by XPS, SEM, and EDX. SEM confirmed 
homogeneous film growth (data not shown). We determined the PtNi ratio to be 1:1 by XPS. All PtNi films were used in the experiments without further cleaning.

\subsection{Cyclic Voltammetry}

Cyclic voltammetry was performed in $0.1 \mathrm{M} \mathrm{HClO}_{4}$ in hanging meniscus configuration between 0.05 and $0.9 \mathrm{~V}_{\mathrm{RHE}}$. The scan rate was $50 \mathrm{mVs}^{-1}$ and 5 cycles were taken per $\mathrm{CV}$. The cycles show good reproducibility and for all voltammograms we display the second cycle only. Before each CV measurement, the potential cycling was performed as described in Section 3.1. Figure $2 \mathrm{a}$ and $2 \mathrm{~b}$ show both positive and negative scans, while for clarity in Figure $2 \mathrm{c}$ and $2 \mathrm{~d}$ only the positive scan direction is displayed.

$\operatorname{Pt}(111)$ : The CVs of $\operatorname{Pt}(111)$ (see Figure 2a and 2c) after potential cycling between 0.05 and 0.9

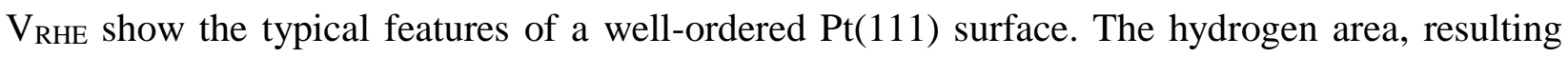
from the oxidation/reduction of hydrogen for positive/negative scan directions, extends from 0.05 to $0.4 \mathrm{~V}_{\mathrm{RHE}}$. It is flat as previously reported for clean low-defect $\operatorname{Pt}(111)$ surfaces ${ }^{[19 \mathrm{~b}]}$ and shows a very weak feature at $0.29 \mathrm{~V}_{\mathrm{RHE}}$ only, indicating the existence of very small amount of Pt[100] steps. Above the double layer region (0.4 - $\left.0.6 \mathrm{~V}_{\mathrm{RHE}}\right)$ we observe the characteristic oxygen region between 0.6 and $0.9 \mathrm{~V}_{\mathrm{RHE}}$, with a sharp "butterfly" with peaks at $0.80 \mathrm{~V}_{\mathrm{RHE}}$ for both positive and negative scan directions. The oxygen region mainly results from $\mathrm{OH}^{-}$adsorption on the $\operatorname{Pt}(111)$ surface produced by the activation of water. ${ }^{[19 \mathrm{~b}, 27]}$ For a more detailed discussion of the voltammogram of $\operatorname{Pt}(111)$ in perchloric acid we refer to the literature. ${ }^{[28]}$

Next, we consider the changes in the CV upon cycling to higher potential (see Figure 2). When increasing the upper potential limit up to $1.2 \mathrm{~V}_{\mathrm{RHE}}$, the shape of the voltammogram stays quite stable, indicating that no irreversible changes occur on the $\operatorname{Pt}(111)$ surface. At $1.2 \mathrm{~V}_{\mathrm{RHE}}$, high coverages of adsorbed oxygen are formed. ${ }^{[29]}$ This process is accompanied by considerable changes in the surface morphology. In the hydrogen region, two sharp peaks appear at 0.13 and $0.29 \mathrm{~V}_{\mathrm{RHE}}$. The peak at $0.13 \mathrm{~V}_{\mathrm{RHE}}$ can be assigned to hydrogen adsorption at Pt[110] steps, while the peak at $0.29 \mathrm{~V}$ is associated with hydrogen at the Pt[100] steps. ${ }^{[29-30]}$ The observation that the peak at 0.13 $\mathrm{V}_{\mathrm{RHE}}$ becomes more pronounced than the peak at $0.29 \mathrm{~V}_{\mathrm{RHE}}$ is well known for CV in perchloric acid. ${ }^{[29,31]}$ In addition the oxygen region changes drastically and the sharp butterfly at $0.8 \mathrm{~V}_{\mathrm{RHE}}$ disappears. Again, this indicates the formation of defects and the loss of ordered (111) terraces. 
When the upper potential limit is increased further, the Pt[110] step signal in the hydrogen region at $0.13 \mathrm{~V}_{\mathrm{RHE}}$ becomes larger, while the $\mathrm{OH}$ peak at $0.80 \mathrm{~V}_{\mathrm{RHE}}$ vanishes completely.

PtNi: We investigated the PtNi film using the same procedure as applied for the Pt(111) sample. The corresponding CVs are shown in Figure $2 \mathrm{~b}$ and $2 \mathrm{~d}$. For the PtNi catalyst cycled between 0.05 and $0.9 \mathrm{~V}_{\mathrm{RHE}}$ we observe the typical features of a polycrystalline Pt surface. Between 0.05 and 0.36 $\mathrm{V}_{\mathrm{RHE}}$ there is a curved hydrogen region with a maximum at $0.18 \mathrm{~V}_{\mathrm{RHE}}$, but no distinct additional features. The $\mathrm{OH}$ adsorption/desorption is found between 0.6 and $0.9 \mathrm{~V}_{\mathrm{RHE}}$ without the characteristic features of the ordered $\mathrm{Pt}(111)$ surface. Increasing stepwise the upper potential limit from 0.9 to $1.1 \mathrm{~V}_{\mathrm{RHE}}$ resulted in no changes in the shape of the CVs. However, several new features appeared upon cycling above $1.1 \mathrm{~V}_{\text {RHE}}$. In the hydrogen area, we observe two additional shoulders at 0.14 and $0.32 \mathrm{~V}_{\text {RHE. }}$ We assign these features to the [110] and [100] step sites discussed above. In the $\mathrm{OH}$ region, a shoulder becomes visible at $0.85 \mathrm{~V}_{\mathrm{RHE}}$ after cycling to $1.2 \mathrm{~V}_{\mathrm{RHE}}$. This potential coincides with the potential range reported for $\mathrm{Pt}$ dissolution from polycrystalline $\mathrm{Pt} .{ }^{[11 \mathrm{a}]}$ This indicated the onset of major structural changes which will be discussed in more detail in the next section.

\subsection{Atomic Force Microscopy of PtNi Thin Film Catalysts}

We performed EC-AFM investigations to obtain further information on the structural transformation of the PtNi thin film catalyst. All experiments were performed in $0.1 \mathrm{M} \mathrm{H}_{2} \mathrm{SO}_{4}$ using a potential cycling procedure equivalent to that used in the CV experiments. In Figure 3, selected AFM images are shown after cycling to different potential limits, together with particle size distributions obtained from the microscopy images. The complete series of images obtained in the cycling experiments is provided in the Supporting Information (see Figures S1 and S2).

A homogeneous film of PtNi nanoparticles is observed for the as prepared film with no cracks or holes visible. The particle size is rather well-defined and the average nanoparticle diameter is around $10 \mathrm{~nm}$. It should be mentioned, however, that the particles in AFM appear larger due to convolution with the AFM tip shape. Therefore, we restrict our discussion to qualitative changes only. After potential cycling to $0.9 \mathrm{~V}_{\mathrm{RHE}}$ first cracks appear in the PtNi film. In a previous study, we observed similar cracking behavior on magnetron sputtered PtCo catalysts upon cycling to 1.5 $\mathrm{V}_{\text {RHE. }}{ }^{[17 \mathrm{a}]}$ The present results imply that some material loss already occurs during cycling at 
moderate conditions. We associate this process with the dissolution of $\mathrm{Ni}$, mainly from surface sites and pores in the film. As a result, the particle volume decreases which is also reflected by the finding that the experimentally determined particle size measured by AFM decreases to $8.8 \mathrm{~nm}$.

More drastic changes occur upon cycling to $1.2 \mathrm{~V}_{\mathrm{RHE}}$, which is reported to be the potential limit for $\mathrm{Pt}$ dissolution of polycrystalline $\mathrm{Pt}{ }^{[10]}$ At this potential, the heterogeneity of the surface increases while the measured particle size decreases to $7.4 \mathrm{~nm}$. An increased roughness of the surface is in accordance with the changes observed in CV discussed above. We associate the structural changes with an enhanced dissolution of bulk $\mathrm{Ni}$, which was previously protected by a metallic Pt shell, formed under the electrochemical conditions of the experiment. ${ }^{[4]}$ At higher cycling potentials (see Figure 3,1.5 $\mathrm{V}_{\mathrm{RHE}}$ ) the trend is reversed and the particle size increases again. Simultaneously, the formation of a large number of cracks is observed. We associate this effect with the dissolution and redeposition of $\mathrm{Pt}$, leading to the growth of larger monometallic $\mathrm{Pt}$ nanoparticles by Ostwald ripening. ${ }^{[12]}$ Additionally, agglomeration and coalescence may contribute to the broadening of the particle size distribution. ${ }^{[2 a]}$

\subsection{IR Spectroscopy}

We performed electrochemical in-situ IR spectroscopy in order to explore the chemical nature of the adsorption sites exposed by the alloy particles during the different stages of potential-dependent restructuring. We used CO as an IR probe molecule, which is well-studied on Pt surfaces and very sensitive to the chemical environment and surface structure ${ }^{[32]}$ The electrooxidation of $\mathrm{CO}$ is a widely investigated reaction in electrochemistry, both on flat single crystalline Pt surfaces as well as on stepped and polycrystalline electrodes. ${ }^{[33]}$ It is proposed that the reaction takes place via a Langmuir-Hinshelwood mechanism involving $\mathrm{CO}_{\text {ads }}$ and a neighboring $\mathrm{OH}_{\text {ads }}$ resulting from the oxidation of water. $\mathrm{COOH}_{\mathrm{ads}}$ is formed in the rate-determining step as an intermediate, which is oxidized in a further step to $\mathrm{CO}_{2}{ }^{[33 \mathrm{f}]}$

The potential cycling procedure applied between the measurements was described in Section 3.1 (see Figure 1). Before each measurement, we adsorbed $\mathrm{CO}$ on the catalysts for $4 \mathrm{~min}$ at $0.05 \mathrm{~V}_{\mathrm{RHE}}$ in retracted position (see Figure 1, step 2a) and then measured IR spectra in thin layer configuration during $\mathrm{CO}$ oxidation by a stepwise increase in the potential between 0.05 and $0.9 \mathrm{~V}_{\mathrm{RHE}}$. 
Pt(111): First, we measured the $\mathrm{CO}$ oxidation on the $\mathrm{Pt}(111)$ reference without any previous potential cycling (see Figure 4). We observe three CO bands between 2100 and $1750 \mathrm{~cm}^{-1}$ : The most pronounced band is the $\mathrm{CO}$ on-top $\left(\mathrm{CO}_{\mathrm{t}}\right)$ band between 2065 and $2074 \mathrm{~cm}^{-1}$. Initially, this band exhibits bipolar shape. Due to the Stark effect, it shifts from $2068 \mathrm{~cm}^{-1}$ at $0.1 \mathrm{~V}_{\mathrm{RHE}}$ to 2074 $\mathrm{cm}^{-1}$ at $0.5 \mathrm{~V}_{\mathrm{RHE}}$ (Stark slope of $16 \pm 1 \mathrm{~cm}^{-1} \mathrm{~V}^{-1}$ ). At higher potential, the band becomes negative indicating that $\mathrm{CO}_{\mathrm{t}}$ is consumed by oxidation. The formed $\mathrm{CO}_{2}$ dissolves in the electrolyte and gives rise to the band at $2343 \mathrm{~cm}^{-1}$ (present in both $\mathrm{s}$ and p polarization, not shown). After complete consumption of the $\mathrm{CO}_{\mathrm{t}}$, the loss band is observed at $2065 \mathrm{~cm}^{-1}$, representing the $\mathrm{CO}$ band position at the reference potential of $0.05 \mathrm{~V}_{\mathrm{RHE}}$. Beside the on-top $\mathrm{CO}$, a threefold hollow $\mathrm{CO}_{3 \mathrm{f}}$ species is

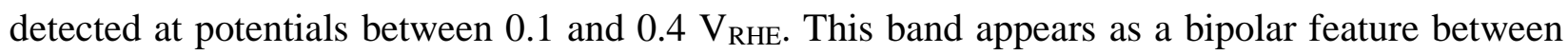
1786 and $1797 \mathrm{~cm}^{-1}$ with a Stark slope of $37 \pm 3 \mathrm{~cm}^{-1} \mathrm{~V}^{-1}$ and transforms into a loss band at 1779 $\mathrm{cm}^{-1}$ at a potential of $0.5 \mathrm{~V}_{\mathrm{RHE}}$. While the band of $\mathrm{CO}_{3 \mathrm{f}}$ disappears, a third $\mathrm{CO}$ band rises at 1844 $\mathrm{cm}^{-1}$. This feature can be assigned to bridge bonded $\mathrm{CO}_{\mathrm{b}}$, and indicates the transition from the $(2 \times$ 2) $\mathrm{CO}$ adlayer to the $(\sqrt{ } 19 \times \sqrt{ } 19)$ structure. ${ }^{[34]}$ The $\mathrm{CO}_{\mathrm{b}}$ band shifts to $1849 \mathrm{~cm}^{-1}$ at $0.6 \mathrm{~V}_{\mathrm{RHE}}$ before oxidation at higher potentials leads to disappearance of this band. All bands and potentials agree well with results of previous in-situ IR investigations of the $\mathrm{CO}$ oxidation on $\mathrm{Pt}(111)$ in acidic media. ${ }^{[34]}$

In the next step, the $\mathrm{Pt}(111)$ was cycled to increasing potentials following the procedure described in Section 3.1 and Figure 1, while repeating the $\mathrm{CO}$ oxidation experiment after each cycling step. The complete set of IR data is provided in the Supporting Information (see Figure S3). For cycling up to a potential limit of $1.2 \mathrm{~V}_{\mathrm{RHE}}, \mathrm{CO}$ band positions and intensities are identical to those of the as-prepared $\operatorname{Pt}(111)$ sample. This shows that up to a potential of $1.2 \mathrm{~V}_{\mathrm{RHE}}$, no structural changes occur on the surface, in accordance with our conclusions from cyclic voltammetry.

Drastic changes are observed, however, upon cycling to higher potential. In Figure 4 we present

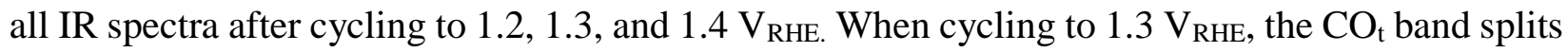
into distinct features. At $0.1 \mathrm{~V}_{\mathrm{RHE}}$, for instance, we can distinguish between a slightly blue component at $2072 \mathrm{~cm}^{-1}$ and a slightly redshifted one at $2067 \mathrm{~cm}^{-1}$. At higher potential, the two bands overlap to form a broader feature. Rodes et al. investigated the influence of steps on $\operatorname{Pt}(111)$ on the CO IR signals. They observed a blue shift in the presence of [110] steps and a redshift in the presence of [100] steps. ${ }^{[34]}$ Based on their results and our CV data we assign the two shifted features 
at 2072 and $2067 \mathrm{~cm}^{-1}$ to the presence of [110] and [100] steps, respectively. In the spectral range of threefold-hollow and bridge-bonded $\mathrm{CO}$, we observe that the bands become less intense and the bridge-bonded $\mathrm{CO}$ is formed at $0.4 \mathrm{~V}_{\mathrm{RHE}}$, i.e. at $0.1 \mathrm{~V}$ lower potential than for the as-prepared $\operatorname{Pt}(111)$. These changes are also associated with higher defect density. ${ }^{[34]}$

Upon cycling to $1.4 \mathrm{~V}_{\mathrm{RHE}}$, the $\mathrm{CO}_{\mathrm{b}}$ and $\mathrm{CO}_{3 \mathrm{f}} \mathrm{CO}$ bands vanish almost completely, while the $\mathrm{CO}_{\mathrm{t}}$ band increases in intensity. The blue shifted $\mathrm{CO}_{\mathrm{t}}$ component, previously assigned to [110] steps, becomes dominant (see Figures $4 \mathrm{~b}$ and 6a), suggesting that the [110] are the prevailing defect structure. This observation is in agreement with the data obtained from cyclic voltammetry.

The characteristic behavior of the $\mathrm{CO}_{\mathrm{t}}$ band upon potential cycling is best seen in a direct comparison at the same potential. In Figure $6 \mathrm{a}$, we display the $\mathrm{CO}_{\mathrm{t}}$ region measured at $0.8 \mathrm{~V}_{\mathrm{RHE}}$ after cycling to different potential limits. The corresponding band positions as a function of the potential limit are shown in Figure 6c. In accordance with the above discussion, no changes are observed up to $1.2 \mathrm{~V}_{\mathrm{RHE}}$. At cycling to $1.3 \mathrm{~V}_{\mathrm{RHE}}$, the $\mathrm{CO}_{\mathrm{t}}$ band splits into a blue-shifted component from [110] steps and the red-shifted one from [100] steps, with the former feature becoming dominant at higher potential.

PtNi: Based on the data on $\operatorname{Pt}(111)$, we investigated the PtNi thin-film catalyst in an equivalent experiment. The corresponding data is shown in Figure 5 and in the Supporting Information (Figure S4). First, we note that the $\mathrm{CO}_{2}$ band at $2343 \mathrm{~cm}^{-1}$, which indicates the onset of the $\mathrm{CO}$ oxidation, appears at $0.2 \mathrm{~V}_{\text {RHE}}$, i.e. at $0.1 \mathrm{~V}$ lower potentials as compared to $\mathrm{Pt}(111)$ surface. $\mathrm{CO}_{3 f}$ is not found on the alloy film. A loss-signal in the bridge-bonded CO region between 1873 and $1896 \mathrm{~cm}^{-1}$ indicates the presence of $\mathrm{CO}_{\mathrm{b}}$ already at the reference potential, with $\mathrm{CO}_{\mathrm{b}}$ fully oxidized at 0.4 $\mathrm{V}_{\text {RHE. This }}$ is in strong contrast to the $\mathrm{Pt}(111)$ surface, where $\mathrm{CO}_{\mathrm{b}}$ is formed only at $0.5 \mathrm{~V}_{\mathrm{RHE}}$ and is oxidized above $0.6 \mathrm{~V}_{\mathrm{RHE}}$. Drastic changes take place in the $\mathrm{CO}_{\mathrm{t}}$ region, where two bands are observed. We assign the dominant band between 2061 and $2069 \mathrm{~cm}^{-1}$ with a Stark slope of $14 \pm 3$ $\mathrm{cm}^{-1} \mathrm{~V}^{-1}$ to $\mathrm{CO}_{\mathrm{t}}$ adsorbed on Pt sites. In addition, a shifted $\mathrm{CO}_{\mathrm{t}}$ band is observed between 2074 and $2076 \mathrm{~cm}^{-1}$. Based on DFT calculations, we will show later that this second band can be associated with a low-coordinated carbonyl-like Pt species. Both bands transform into loss features at 0.4 $\mathrm{V}_{\mathrm{RHE}}$ indicating the oxidation of on-top CO. 
In Figure $6 \mathrm{~b}$, the $\mathrm{CO}_{\mathrm{t}}$ region of the PtNi catalysts is shown at $0.8 \mathrm{~V}_{\mathrm{RHE}}$ in dependence of the upper cycling potential limit. Upon cycling to $1.1 \mathrm{~V}_{\mathrm{RHE}}$ the blue-shifted $\mathrm{CO}_{\mathrm{t}}$ band decreases in intensity and finally disappears. Simultaneously, the main $\mathrm{CO}_{\mathrm{t}}$ signal shifts slightly from $2061 \mathrm{~cm}^{-1}$ to 2064 $\mathrm{cm}^{-1}$. Cycling to $1.2 \mathrm{~V}_{\mathrm{RHE}}$ both band position and shape change drastically. The $\mathrm{CO}_{\mathrm{t}}$ band becomes very broad and its peak position undergoes pronounced red-shifts to $2044 \mathrm{~cm}^{-1}$ (see also peak positions in Figure 6c). As it will be discussed below in conjunction with the DFT models, we associate these spectral changes with changes in the chemical environment of $\mathrm{Pt}$, i.e. the presence of $\mathrm{Ni}$ in the Pt coordination sphere. Noteworthy, the potential limits, where we detect the strongest changes in the IR spectra agree well with those in the cyclic voltammetry and AFM experiments.

Cycling to $1.3 \mathrm{~V}_{\mathrm{RHE}}$, the $\mathrm{CO}_{\mathrm{t}}$ band shifts back to higher wavenumbers and becomes sharper again. At $1.4 \mathrm{~V}_{\mathrm{RHE}}$, the band position reaches the same wavenumbers as measured before at potential limits below 1.2 $\mathrm{V}_{\text {RHE. }}$. Besides the spectral shifts, we observe that at potential limits above 1.3 $\mathrm{V}_{\mathrm{RHE}}$ the intensity of the $\mathrm{CO}$ bands also decreases rapidly. We assign this effect to the decrease of the active Pt surface area caused by Ostwald ripening. This agrees well with the results obtained by in-situ AFM measurements discussed in Section 3.3.

\subsection{DFT Calculations and Potential Dependent Changes of Surface Structure and Composition}

To interpret the potential dependent changes in the CO IR spectra, we calculated the CO stretching frequencies on various PtNi model nanoparticles (NPs) and surfaces using DFT. Figure 7 shows an overview of all models used, including the calculated $\mathrm{CO}$ adsorption energies and the corresponding $\mathrm{CO}$ stretching frequencies.

Two differently sized nanoparticles were used in the calculations, a smaller particle with 79 atoms and a larger nanoparticle model with 140 atoms. First the $\mathrm{CO}$ stretching frequencies on the pure $\mathrm{Pt}$ NPs (see Figure 7, models i, iv) were calculated as a reference. $\mathrm{CO}$ was adsorbed on one of the (111) facets, like it is depicted in Figure 7. In our previous works, we systematically investigated already the stretching frequencies of $\mathrm{CO}$ on $\mathrm{Pt}$ atoms with lower coordination numbers, i.e. edge and corner sites in NPs and low-coordinated sites in clusters. We refer to these works for details. ${ }^{[26 \text {, }}$ ${ }^{35]}$ Here we focus on the role of alloying effects only. 
Note that a direct comparison of the absolute $\mathrm{CO}$ stretching frequencies in experiment and calculation is complicated due to dynamic coupling effects and potential-dependent interfacial electric fields (Stark effect). To circumvent these difficulties, we restrict our discussion to relative shifts of the CO stretching frequency only, using pure Pt particles and $\mathrm{Pt}(111)$ as a reference. To explore the "ligand" effect of Ni neighbors on the adsorption properties of the Pt atoms, Pt atoms in the NP were exchanged by Ni in different arrangements. In models (ii) and (v), we replaced one (111) Pt facet by Ni atoms with the exception of the Pt atom on which the $\mathrm{CO}$ is adsorbed. As a result, the $\mathrm{Pt}$ atom, which binds to the $\mathrm{CO}$, has $6 \mathrm{Ni}$ neighbors and $3 \mathrm{Pt}$ neighbors in the second layer. We obtain substantially red-shifted $\mathrm{CO}$ stretching frequencies, by $-23 \mathrm{~cm}^{-1}$ for $\mathrm{Pt}_{68} \mathrm{Ni}_{11}$ (model ii) and $-31 \mathrm{~cm}^{-1}$ for $\mathrm{Pt}_{123} \mathrm{Ni}_{17}$ (model v). Under electrochemical conditions, however, it is more likely that $\mathrm{Ni}$ is leached from the surface and can remain in the subsurface region only. To mimic this situation, we used nanoparticle models in which the subsurface Pt layer was exchanged by $\mathrm{Ni}$ (see Figure 7, model iii and model vi). In these models the number of Ni neighbors is 3 for the $\mathrm{CO}$-adsorbing Pt atom. The calculated frequency shifts are also lower, yielding red-shifts of -15 $\mathrm{cm}^{-1}$ and $-21 \mathrm{~cm}^{-1}$ for $\mathrm{Pt}_{60} \mathrm{Ni}_{19}$ (model iii) and $\mathrm{Pt}_{115} \mathrm{Ni}_{25}$ (model vi), respectively. These shifts are in good agreement with the red-shifts observed after potential cycling to $1.2 \mathrm{~V}_{\text {RHE}}$. Still, we tested further surface structures that may lead to similar shifts. One possibility is to adsorb CO on diluted $\mathrm{Ni}$ atoms at the particle surface. This situation was modeled by a single Ni atom embedded in one (111) facet of the Pt NPs, with (model viii and ix) or without (model vii) a subsurface Ni layer. Also, these models lead to a red-shift of the $\mathrm{CO}$ stretching frequency by $17 \mathrm{~cm}^{-1}$ (model vii), 27 $\mathrm{cm}^{-1}$ (model viii), and $36 \mathrm{~cm}^{-1}$ (model ix) with respect to the pure Pt models. Finally, we may assume that $\mathrm{OH}$ groups may co-adsorb on metastable neighboring $\mathrm{Ni}$ atoms at the surface. In models (x) to (xiii) we co-adsorbed 1-6 OH-groups on Ni atoms next to the Pt atom adsorbing CO. The addition of $\mathrm{OH}$-groups leads to a further red-shift of the $\mathrm{CO}$ stretching frequency as compared to the $\mathrm{OH}$-free system (model ii) by up to $28 \mathrm{~cm}^{-1}$.

Various effects may contribute to the broadening and red-shift of the $\mathrm{CO}$ stretching frequency at a cycling limit of $1.2 \mathrm{~V}_{\text {RHE}}$. The calculated stretching frequencies are summarized in Table 1. In view of the lack of stability of surface Ni in this potential region, subsurface Ni structures appear most likely. Therefore, we suggest the following restructuring mechanism: by oxidizing the protective Pt shell at 1.2 $\mathrm{V}_{\mathrm{RHE}}$, Ni migrates to the surface region from the bulk and forms a Ni-enriched subsurface layer. Upon reduction, rough metallic nanoalloy particles are formed, which expose a 
Pt shell, but contain a high concentration of Ni in the subsurface region. During CO oxidation, the ligand-effect of the subsurface Ni atoms together with the exposed low-coordinated Pt sites (see Ref. 26) then leads to the strong red-shift and broadening. When cycling to potentials of $1.3 \mathrm{~V}_{\mathrm{RHE}}$ and above, Pt is completely oxidized, dissolved and redeposited. In this process, Ni is leached from the surface layers, yielding a pure Pt shell, in accordance with the IR spectra that are indicative for rough or polycrystalline Pt surface.

The second new feature in the IR spectra of $\mathrm{CO}$ on the PtNi catalyst that requires an explanation is the strongly blue shifted $\mathrm{CO}_{\mathrm{t}}$ component found at potential cycling up to $1.0 \mathrm{~V}_{\mathrm{RHE}}$ (see Figure $6 \mathrm{~b}$ ). The DFT models discussed above show that this feature is associated neither with Ni species in the surface or subsurface region nor with the co-adsorption of $\mathrm{OH}$. Another process that has to be taken into consideration is the leaching of Ni from the outermost surface layer of the PtNi particle. This process is assumed to take place upon immersion of the film into the electrolyte and will leave behind a large number of low-coordinated Pt atoms. In our previous works we have shown, however, that with decreasing coordination number of $\mathrm{Pt}$, the adsorbed $\mathrm{CO}_{\mathrm{t}}$ reveals a systematic red-shift. ${ }^{[26,35]}$ Therefore, simple roughening of the NP surface alone cannot explain this blueshifted band.

To explore the effect of a roughened surface on the CO IR spectra by DFT calculations, we constructed slab models with low-coordinated Pt atoms. In Figure 7, slab models of a $3 \times 3 \operatorname{Pt}(111)$ supercell (4 atomic Pt layers) with one Pt adatom are depicted. If $4 \mathrm{CO}$ molecules are adsorbed on the supercell $\left(\theta_{\mathrm{CO}}=0.44\right)$, one $\mathrm{CO}$ molecule is located on top of the Pt adatom and three $\mathrm{CO}$ molecules are adsorbed on regular Pt atoms of the (111) facet. The coupled CO modes are calculated to appear at 2087, 2051, 2041 and $2029 \mathrm{~cm}^{-1}$, with the first frequency representing the in-phase coupled stretching mode that will give rise to the most intense band in EC-IRRAS. We can compare these frequencies to those computed for the slab models of ideal Pt(111) surface at different coverages (see Table 2). The calculations predict a blue shift of approximately $7 \mathrm{~cm}^{-1}$ with increasing coverage from $\theta_{\mathrm{CO}}=0.11$ to $\theta_{\mathrm{CO}}=0.33$ and a band position of $2086 \mathrm{~cm}^{-1}$ at $\theta_{\mathrm{CO}}=0.33$ in good agreement with experiment. ${ }^{[36]}$ The calculated wavenumber values for the ideal $\operatorname{Pt}(111)$ surface $\left(2086 \mathrm{~cm}^{-1}\right)$ and the model with low-coordinated Pt adatom $\left(2087 \mathrm{~cm}^{-1}\right)$ are practically identical, indicating that the mere presence of low-coordinated $\mathrm{Pt}$ atoms does not explain the blueshifted component. 
However, further DFT calculations showed that for the "rough" Pt surface model there are stable adsorbate structures with even higher $\mathrm{CO}$ coverage (see Figure 7 , models xiv and xv, $\theta_{\mathrm{CO}}=0.56$ ). An additional $\mathrm{CO}$ molecule can be adsorbed in form of another on-top CO on Pt adatom (model xiv) or in form of a bridge-bonded CO between the Pt ad-atom and one facet Pt (model xv). The corresponding adsorption energies for the formation of models xiv and xv were calculated to be -1.10 and $-1.09 \mathrm{eV}$, respectively. Whereas the bridging $\mathrm{CO}$ model (xv) gives rise to a slightly blue-shifted in-phase CO mode at $2090 \mathrm{~cm}^{-1}$, the "dicarbonyl" (model xiv) is predicted to show a symmetrically coupled CO stretching mode at $2100 \mathrm{~cm}^{-1}$. This corresponds to a blue shift of the $\mathrm{CO}$ stretching frequency of $13 \mathrm{~cm}^{-1}$ in comparison to the lower coverage structure $\left(\theta_{\mathrm{CO}}=0.44\right.$, see Figure 7, model xiv) and a blue shift of $14 \mathrm{~cm}^{-1}$ with respect to that in the $\operatorname{Pt}(111)$ model at $\left(\theta_{\mathrm{CO}}=0.33\right.$ ). These values agree with the experimentally observed blue shift of $13 \pm 2 \mathrm{~cm}^{-1}$ (see Section 3.3). Thus, we attribute the blue-shifted CO component to dicarbonyl species formed at low-coordinated Pt atoms. We propose that the latter are formed upon the leaching of surface $\mathrm{Ni}$ from the PtNi alloy particles. With increasing cycling potential, the Pt species become increasingly mobile, leading to agglomeration of the low-coordinated $\mathrm{Pt}$ atoms and, therefore, to the disappearance of the dicarbonyl species.

\section{Conclusions}

We systematically investigated the stability, structural transformations and adsorption properties of PtNi nanoalloy thin film electrocatalysts during potential cycling up to electrode potentials between 0.9 and $1.5 \mathrm{~V}_{\mathrm{RHE}}$. All catalyst films were prepared by vacuum-deposition techniques, i.e. magnetron co-sputtering, onto a carbon-protected Au support or onto freshly cleaved HOPG. The electrochemical behavior, structure, morphology and adsorption behavior were investigated using $\mathrm{CV}$, EC-AFM, and EC-IRRAS with CO as probe molecule. Systematic DFT modelling was performed to interpret changes observed in the IR spectra. Additional reference experiments were performed under identical cycling and measurement conditions on $\operatorname{Pt}(111)$ single crystal electrodes to support the interpretation of the CV and EC-IRRAS data. In particular, we conclude the following:

1. Using the potential cycling procedures applied in this work, the well-ordered $\operatorname{Pt}(111)$ surface is structurally stable up to a maximum potential limit of $1.2 \mathrm{~V}_{\mathrm{RHE}}$. Above this value 
the increased mobility of Pt first leads to a transient roughening associated with the formation of [110] and [100] steps (up to $1.3 \mathrm{~V}_{\mathrm{RHE}}$ ) while potential cycling to higher values gives rise to preferential formation of [110] steps. Both types of defects give rise to characteristic features in CV and EC-IRRAS.

2. PtNi nanoalloy catalysts show minor structural changes only upon potential cycling up to an upper potential limit of $1.1 \mathrm{~V}_{\mathrm{RHE}}$. Three characteristic features can be identified in the IR spectra of on-top CO, regular on-top CO adsorbed mainly on (111) facet-like sites, CO adsorbed at low-coordinated $\mathrm{Pt}$ and $\mathrm{Pt}$ atoms with $\mathrm{Ni}$ neighbor atoms, giving rise to a pronounced tailing of the on-top CO band to lower wavenumbers and a characteristic blueshifted shoulder $\left(\Delta v=13 \pm 2 \mathrm{~cm}^{-1}\right)$. Based on DFT calculations we attribute the latter shoulder to a Pt dicarbonyl species formed from low-coordinated Pt atoms that are released upon leaching of $\mathrm{Ni}$ from the surface layer of the PtNi alloy particles. With cycling to increasing potential, the density of these low-coordinated Pt species decreases due to agglomeration.

3. Drastic changes in the morphology and surface composition of the PtNi nanoalloy particles occurs upon potential cycling to $1.2 \mathrm{~V}_{\text {RHE. }} \mathrm{CV}$ indicates the formation of a high density of different sites, and a strongly broadened and red-shifted $\mathrm{CO}$ stretching appears in the IRRAS of adsorbed CO $\left(\Delta v=-20 \mathrm{~cm}^{-1}\right)$. Based on DFT calculations we propose that the new IR band manifests the enrichment of $\mathrm{Ni}$ in the subsurface layer of the PtNi alloy particles, which modifies the $\mathrm{CO}$ adsorption on surface $\mathrm{Pt}$ atoms via an electronic ligand effect. We suggest that the Ni enrichment is triggered by the oxidation of the surface $\mathrm{Pt}$ atoms in this potential region.

4. Upon cycling to even higher potential limits (1.3 to $1.5 \mathrm{~V}_{\mathrm{RHE}}$ ), Pt dissolves and readsorbs on the PtNi nanoalloy particles. This leads, on the one hand, to particle growth via Ostwald ripening and, on the other hand, to complete leaching of Ni from surface and subsurface region of the particles. As a result, we observe a behavior in $\mathrm{CV}$ that is characteristic for pure Pt films and CO spectra in EC-IRRAS that are nearly identical to those obtained on rough Pt surfaces.

These findings suggest that nanoparticular PtNi alloy electrocatalysts are subject to drastic changes in the surface composition and structure as a function of the operation conditions. Indeed, adsorption and catalytic properties may be drastically modified by subsurface Ni. The effect can 
be amplified upon Pt oxidation in a small potential region, but is irreversibly lost at the dissolution limit of the Pt component.

\section{Acknowledgements}

The authors acknowledge financial support by the EU (FP7 NMP project ChipCAT Grant No. 310191), by the Deutsche Forschungsgemeinschaft (DFG), and by the DFG within the Excellence Cluster "Engineering of Advanced Materials" in the framework of the excellence initiative. In addition, we acknowledge support through cooperation with the Helmholtz-Institute ErlangenNürnberg (HI ERN), Forschungszentrum Jülich GmbH. The work has been also supported by the Horizon2020 program of the European Commission (project Materials Networking, Ref. $\mathrm{N}^{\mathrm{o}}$ 692146), COST Action MP1306, the Spanish MINECO (grants CTQ2012-34969 and CTQ201564618-R/FEDER), the Generalitat de Catalunya (grants 2014SGR97 and XRQTC), the Bulgarian Science Fund (project DCOST01/18) and the project LH15277 of the Czech Ministry of Education. Computer resources, technical expertise and assistance were provided by the Red Española de Supercomputación (grants QCM-2016-1-0006 and QCM-2016-2-0020 at Memento computers). 


\begin{tabular}{lllllll}
$\begin{array}{l}\text { Nanoparticle } \\
\text { Model }\end{array}$ & $\mathbf{C o m p o s i t i o n ~}$ & $\begin{array}{l}\mathbf{C O} \\
\text { on }\end{array}$ & $\begin{array}{c}\mathbf{E}_{\text {ads }} \\
{[\mathbf{e V}]}\end{array}$ & $\begin{array}{l}\boldsymbol{v}(\mathbf{C}-\mathbf{O}) \\
{\left[\mathbf{c m}^{-1}\right]}\end{array}$ & $\begin{array}{l}\text { Reference } \\
\text { structure }\end{array}$ & $\begin{array}{l}\text { Frequency shift } \\
\Delta \boldsymbol{v}(\mathbf{C}-\mathbf{O})\left[\mathbf{c m}^{-1}\right]\end{array}$ \\
\hline \hline i & $\mathrm{Pt}_{79}$ & $\mathrm{Pt}$ & -1.99 & 2069 & $\mathrm{i}$ & 0 \\
ii & $\mathrm{Pt}_{68} \mathrm{Ni}_{11}$ & $\mathrm{Pt}$ & -2.05 & 2046 & $\mathrm{i}$ & -23 \\
\hline iii & $\mathrm{Pt}_{60} \mathrm{Ni}_{19}$ & $\mathrm{Pt}$ & -1.41 & 2054 & $\mathrm{i}$ & -15 \\
v & $\mathrm{Pt}_{140}$ & $\mathrm{Pt}$ & -1.64 & 2072 & iv & 0 \\
vi & $\mathrm{Pt}_{123} \mathrm{Ni}_{17}$ & $\mathrm{Pt}$ & -1.97 & 2041 & iv & -31 \\
\hline vii & $\mathrm{Pt}_{115} \mathrm{Ni}_{25}$ & $\mathrm{Pt}$ & -1.16 & 2051 & iv & -21 \\
viii & $\mathrm{Pt}_{78} \mathrm{Ni}_{1}$ & $\mathrm{Ni}$ & -1.54 & 2052 & i & -17 \\
ix & $\mathrm{Pt}_{59} \mathrm{Ni}_{20}$ & $\mathrm{Ni}$ & -1.23 & 2042 & i & -27 \\
\hline x & $\mathrm{Pt}_{114} \mathrm{Ni}_{26}$ & $\mathrm{Ni}$ & -0.74 & 2036 & iv & -36 \\
xi & $\mathrm{Pt}_{68} \mathrm{Ni}_{11}-\mathrm{OH}$ & $\mathrm{Pt}$ & -2.07 & 2039 & ii & -7 \\
xii & $\mathrm{Pt}_{68} \mathrm{Ni}_{11}-(\mathrm{OH})_{2}$ & $\mathrm{Pt}$ & -2.00 & 2039 & ii & -7 \\
xiii & $\mathrm{Pt}_{68} \mathrm{Ni}_{11}-(\mathrm{OH})_{4}$ & $\mathrm{Pt}$ & -2.04 & 2033 & ii & -13 \\
& $\mathrm{Pt}_{68} \mathrm{Ni}_{11}-(\mathrm{OH})_{6}$ & $\mathrm{Pt}$ & -2.18 & 2018 & ii & -28
\end{tabular}

Table 1: Overview of the models used in the DFT calculations and the calculated results. In all cases, $\mathrm{CO}$ is adsorbed in on-top position at the sites shown in Figure 7. For each site, the adsorption energy $\mathrm{E}_{\mathrm{ads}}$, and vibrational frequency $v(\mathrm{C}-\mathrm{O})$ are given. In addition, we provide specific shifts of the vibrational frequency $\Delta v(\mathrm{C}-\mathrm{O})$ relative to reference structures that are discussed in the text. 


\begin{tabular}{|c|c|}
\hline Model & $\begin{array}{l}v(\mathrm{C}-\mathrm{O}) \\
{\left[\mathrm{cm}^{-1}\right]}\end{array}$ \\
\hline \multicolumn{2}{|l|}{ CO on Pt(111) } \\
\hline$(\Theta=0.11)$ & 2079 \\
\hline$(\Theta=0.22)$ & 2083 \\
\hline$(\Theta=0.33)$ & 2086 \\
\hline \multicolumn{2}{|l|}{ CO on $\mathrm{Pt}_{1} / \operatorname{Pt}(111)$} \\
\hline $\mathrm{Pt}(\mathrm{CO}) /(\mathrm{CO})_{3} \operatorname{Pt}(111)$ & $\begin{array}{l}\mathbf{2 0 8 7} \\
(2051,2041,2029)\end{array}$ \\
\hline $\begin{array}{l}\mathrm{Pt}(\mathrm{CO})_{2} /(\mathrm{CO})_{3} \mathrm{Pt}(111) \\
(\text { model xiv) }\end{array}$ & $\begin{array}{l}\mathbf{2 1 0 0} \\
(2051,2041,2039,2034)\end{array}$ \\
\hline $\begin{array}{l}\mathrm{Pt}(\mathrm{CO})_{2} /(\mathrm{CO})_{3} \mathrm{Pt}(111) \\
(\operatorname{model} \mathrm{xv})\end{array}$ & $\begin{array}{l}\mathbf{2 0 9 0} \\
(2054,2051,2023,1992)\end{array}$ \\
\hline
\end{tabular}

Table 2: Overview of the $\mathrm{CO}$ vibrational frequencies on a pristine $\mathrm{Pt}(111)$ surface and that with $\mathrm{Pt}$ adatoms (see Figure 7, models xiv and xv). The wavenumber values given in bold correspond to the in-phase-coupled $\mathrm{CO}$ stretching mode, the values in parentheses correspond to the other $\mathrm{CO}$ stretching modes. 


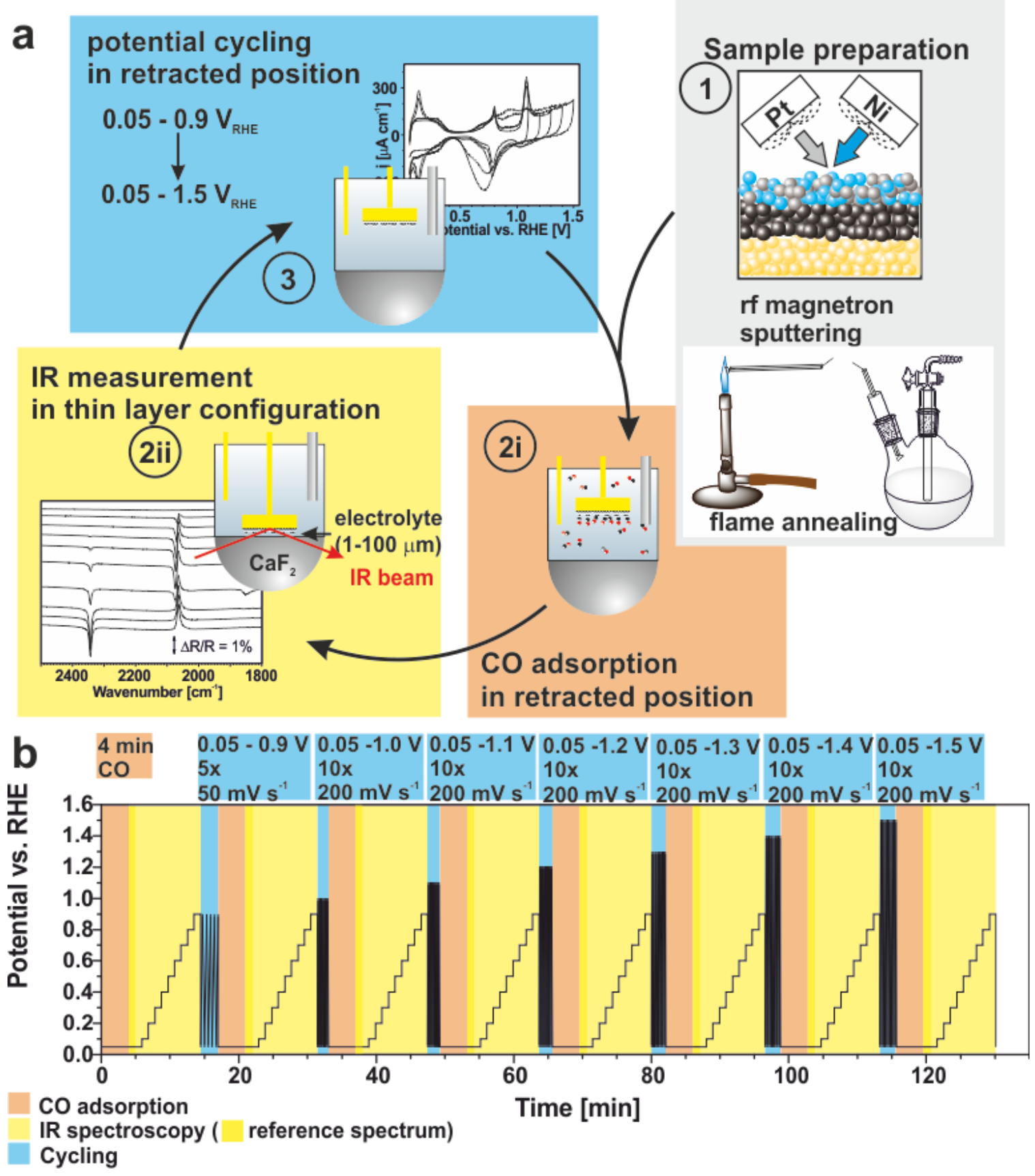

Figure 1: Schematic representations of (a) the experimental procedure and (b) the potential cycling program applied. Step 1 (grey): Sample preparation by rf-magnetron co-sputtering of Pt and Ni onto a carbon-coated Au substrate (catalyst film) and flame annealing ( $\operatorname{Pt}(111)$ reference). Step 2: Measurement procedure. $\mathrm{CO}$ adsorption in retracted sample position at $0.05 \mathrm{~V}_{\mathrm{RHE}}$ (orange) and $\mathrm{CO}$ oxidation in thin-layer configuration (yellow). At each potential step an IR spectrum was recorded. Step 3 (blue): Potential cycling in retraced position. Steps 2 and 3 were repeated for increasing upper potential limits in step 3. 

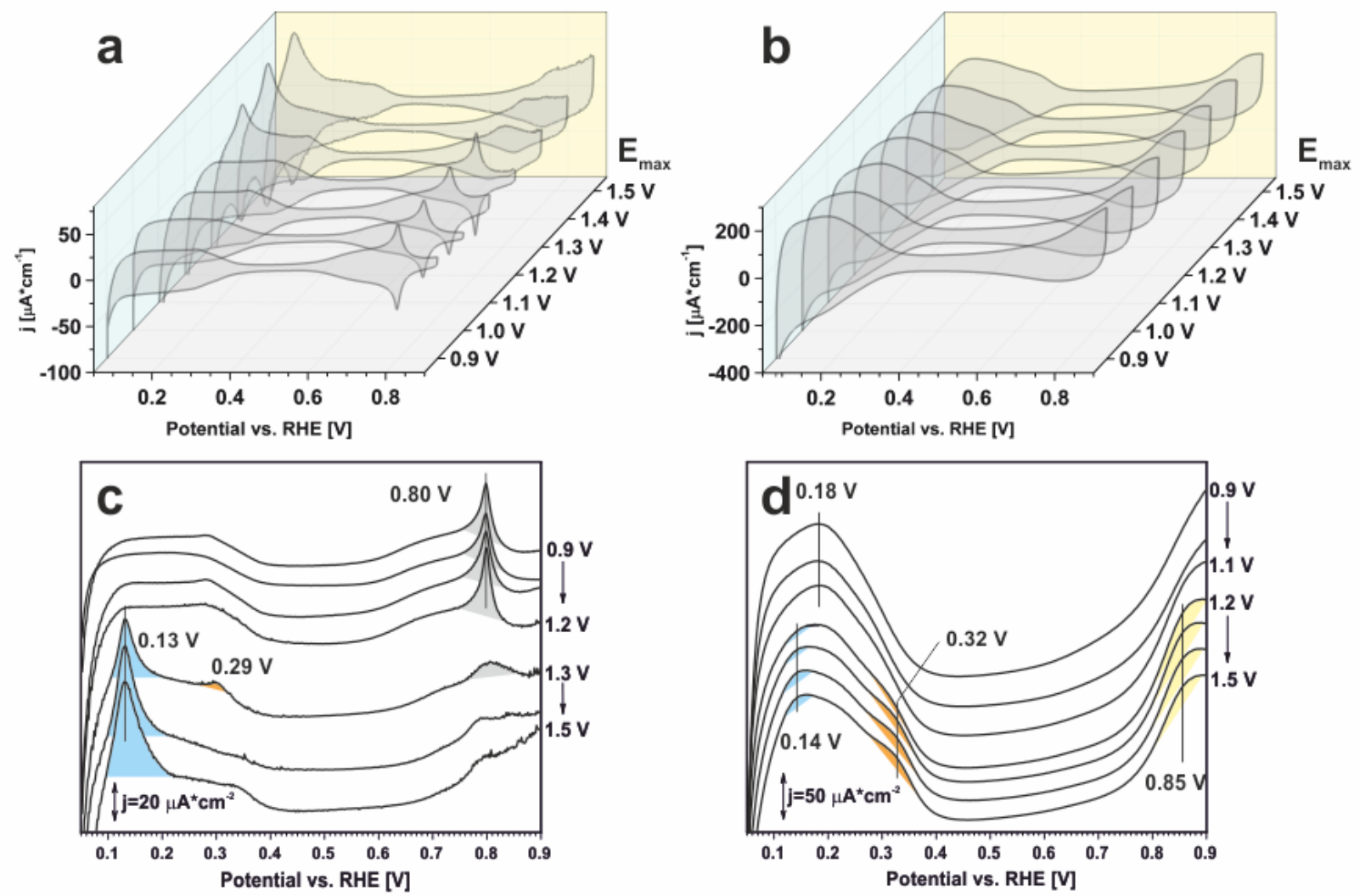

Figure 2: Cyclic voltammograms for (a) the $\mathrm{Pt}(111)$ reference and for (b) the PtNi thin film catalyst in $0.1 \mathrm{M} \mathrm{HClO}_{4}$. Between each of voltammograms a potential cycling step was applied as illustrated in Figure 1. The upper potential limit in the cycling step was increased from $0.9 \mathrm{~V}_{\mathrm{RHE}}$ to 1.5 $\mathrm{V}_{\text {RHE}}$. For a better comparison, only the positive scan direction is shown in the waterfall plot for $\operatorname{Pt}(111)$ (c) and the PtNi thin film catalyst (d). 


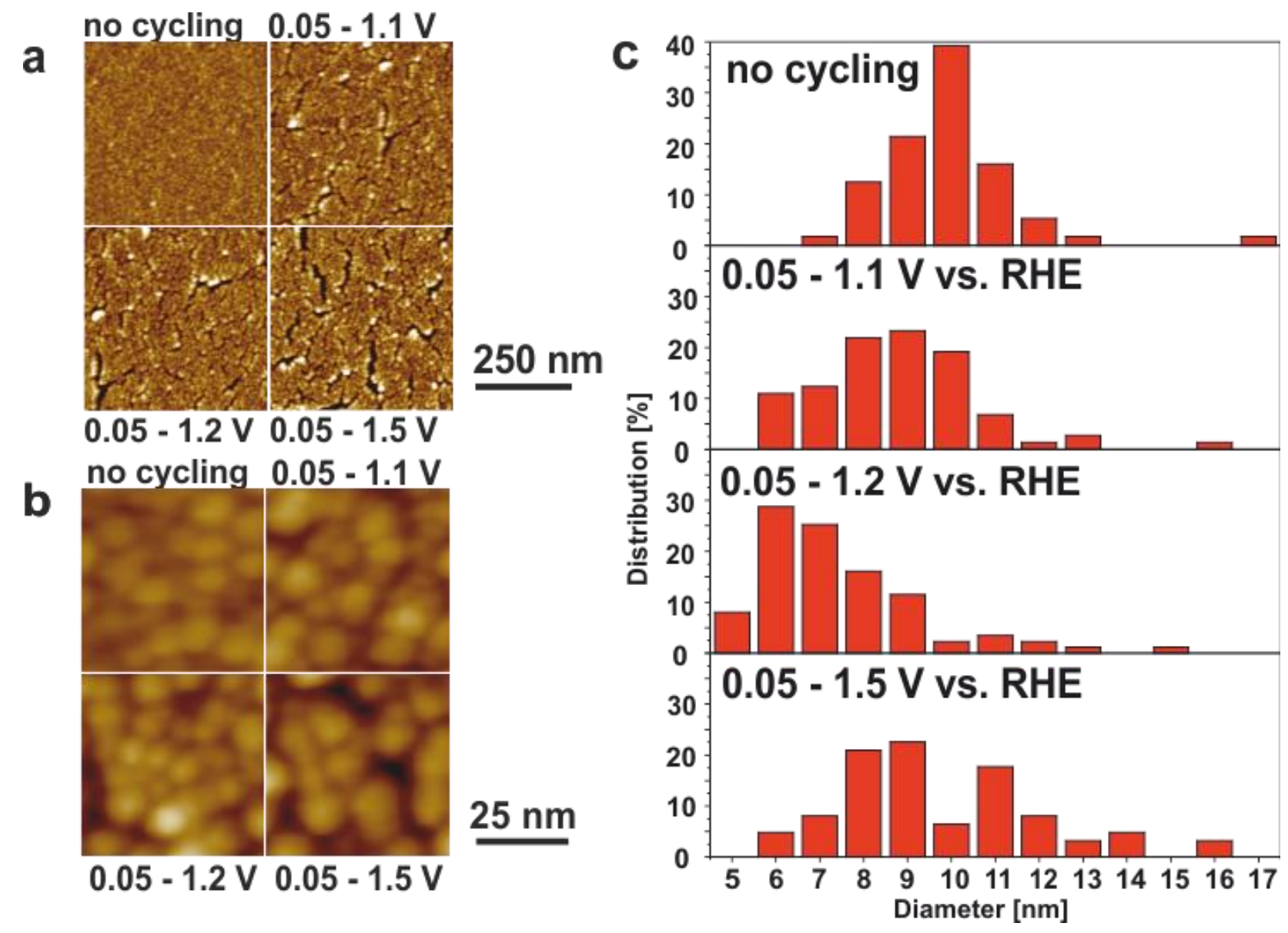

Figure 3: In-situ AFM images of PtNi thin film catalysts before potential cycling, and after potential cycling between $0.05-1.1 \mathrm{~V}_{\mathrm{RHE}}, 0.05-1.2 \mathrm{~V}_{\mathrm{RHE}}$, and $0.05-1.5 \mathrm{~V}_{\text {RHE. }}$ (a) scan area 500 $\mathrm{nm} \times 500 \mathrm{~nm}$, (b), scan area $50 \times 50 \mathrm{~nm}$. (c) particle size distribution as determined from the AFM images. 
a) $\operatorname{Pt}(111)$

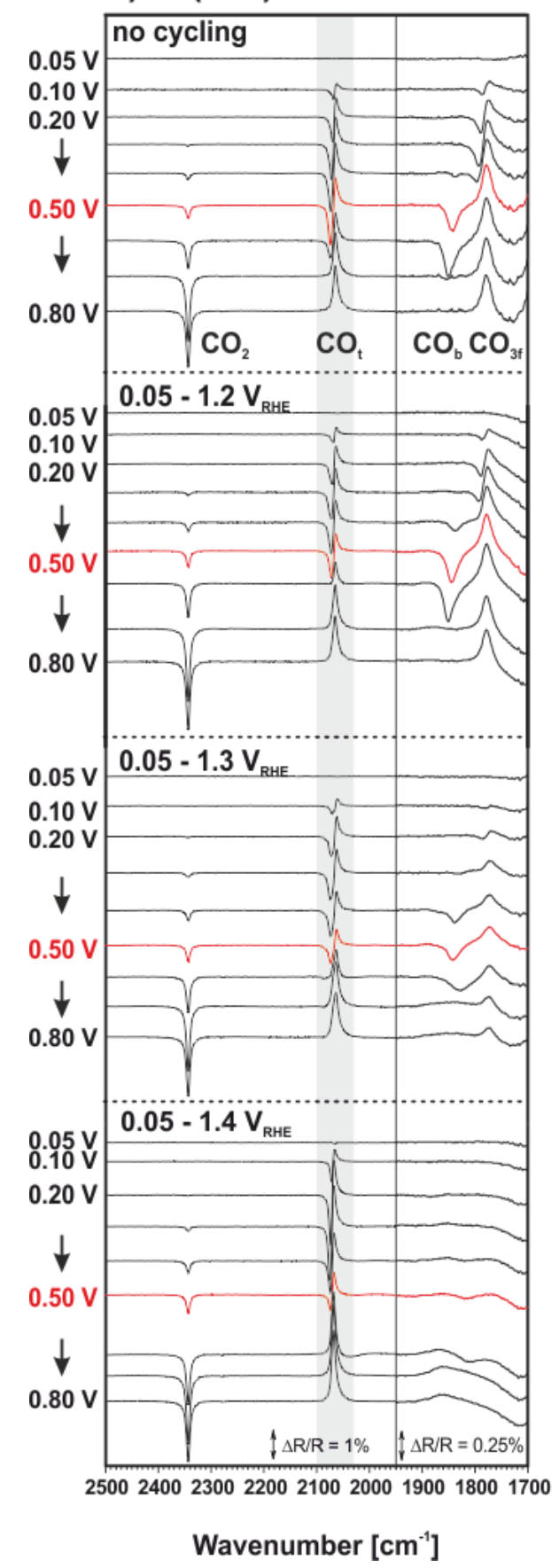

b) $\mathrm{CO}_{\mathrm{t}}$

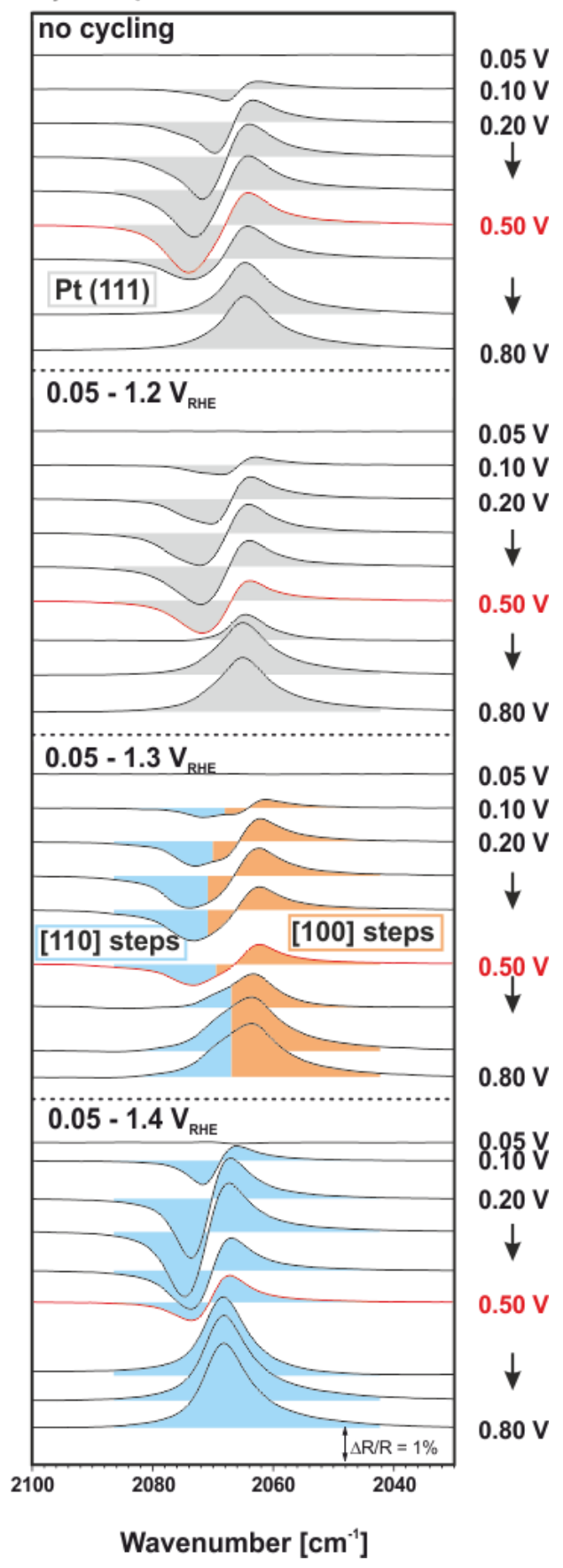

Figure 4: Selected in-situ IR spectra during $\mathrm{CO}$ oxidation in $0.1 \mathrm{M} \mathrm{HClO}_{4}$ on a $\mathrm{Pt}(111)$ electrode in the region of the $\mathrm{CO}$ and $\mathrm{CO}_{2}$ stretching frequencies (a) and details of the $\mathrm{CO}_{\mathrm{t}}$ band (b). The different data sets were taken after cycling to different potentials as described in Figure 1. All reference spectra were taken at $0.05 \mathrm{~V}_{\mathrm{RHE}}$. 
a) PtNi

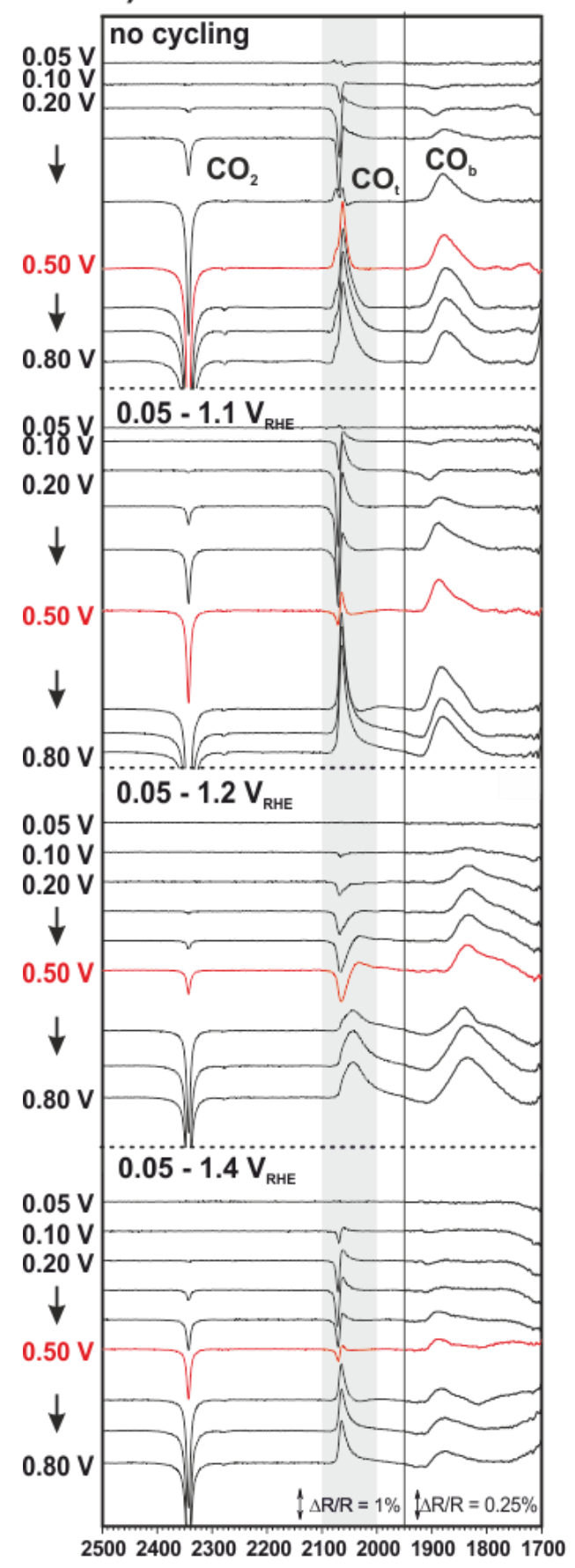

Wavenumber [cm-1] b) $\mathrm{CO}_{\mathrm{t}}$

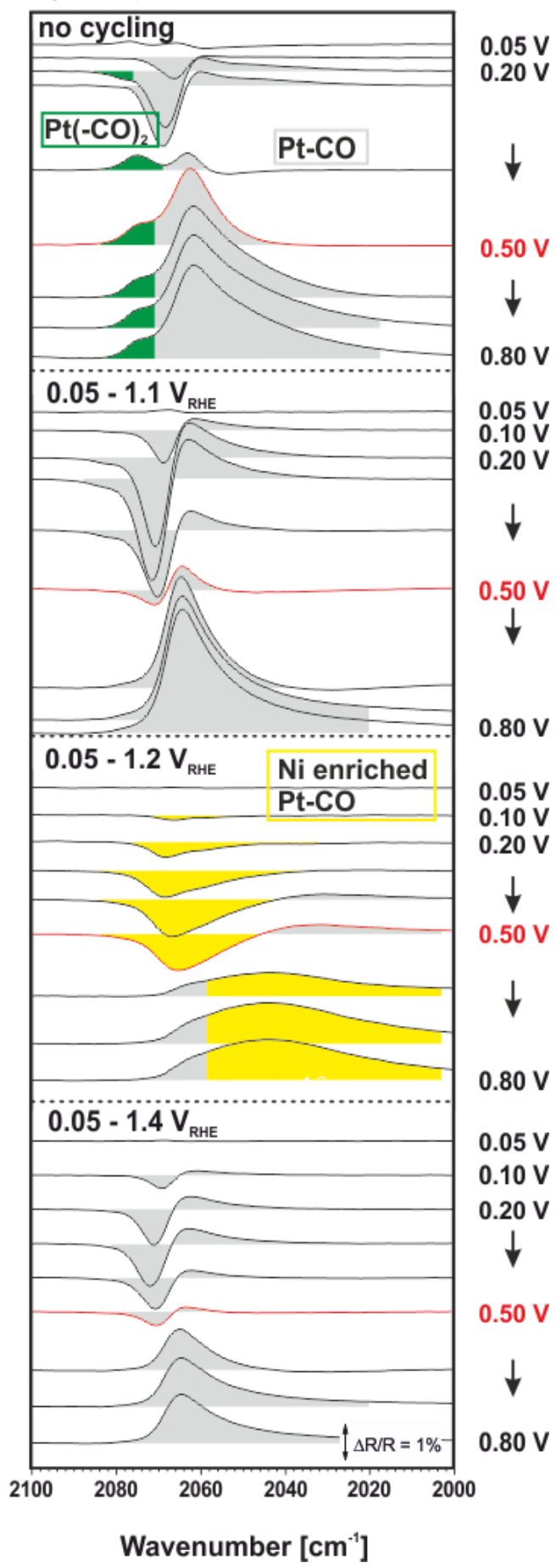

Figure 5: Selected in-situ IR spectra during $\mathrm{CO}$ oxidation in $0.1 \mathrm{M} \mathrm{HClO}_{4}$ on a $\mathrm{Pt}(111)$ electrode in the region of the $\mathrm{CO}$ and $\mathrm{CO}_{2}$ stretching frequencies (a) and details of the $\mathrm{CO}_{\mathrm{t}}$ band (b). The different data sets were taken after cycling to different potentials as described in Figure 1. All reference spectra were taken at $0.05 \mathrm{~V}_{\mathrm{RHE}}$. 

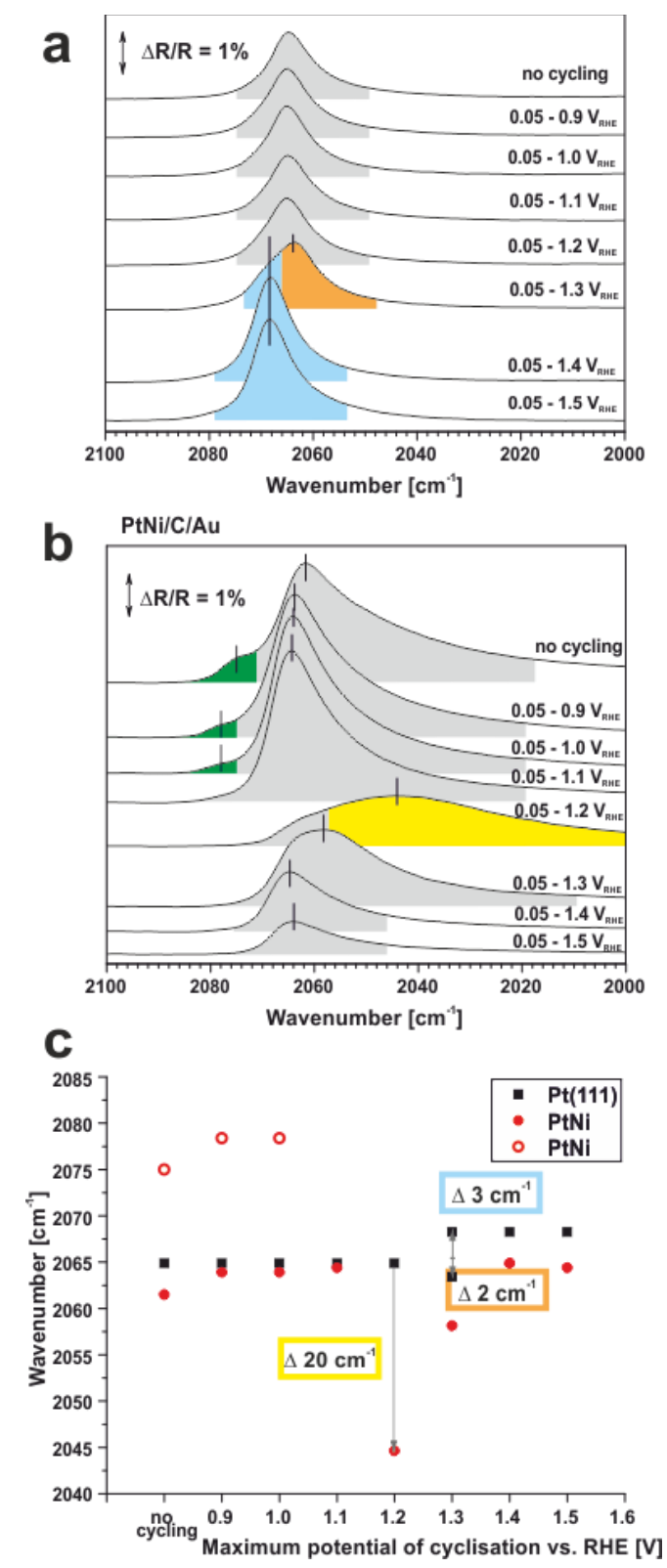

Figure 6: Comparison of the in-situ IR spectra at $0.8 \mathrm{~V}_{\mathrm{RHE}}$ for $\mathrm{CO}$ oxidation on (a) $\mathrm{Pt}(111)$ and on (b) the PtNi thin film catalyst after cycling to different potential. (c) Peak positions of the CO IR bands shown in (a) and (b). Squares in black illustrate the peak position of the $\mathrm{CO}_{\mathrm{t}}$ band on a $\mathrm{Pt}(111)$ surface. Full circles in red are attributed to $\mathrm{CO}_{\mathrm{t}}$ adsorbed on $\mathrm{Pt}$ sites, while empty red circles correspond to an additional blue shifted band on the PtNi catalyst. We assign this blue shifted band to a dicarbonyl species formed from low-coordinated Pt atoms. 

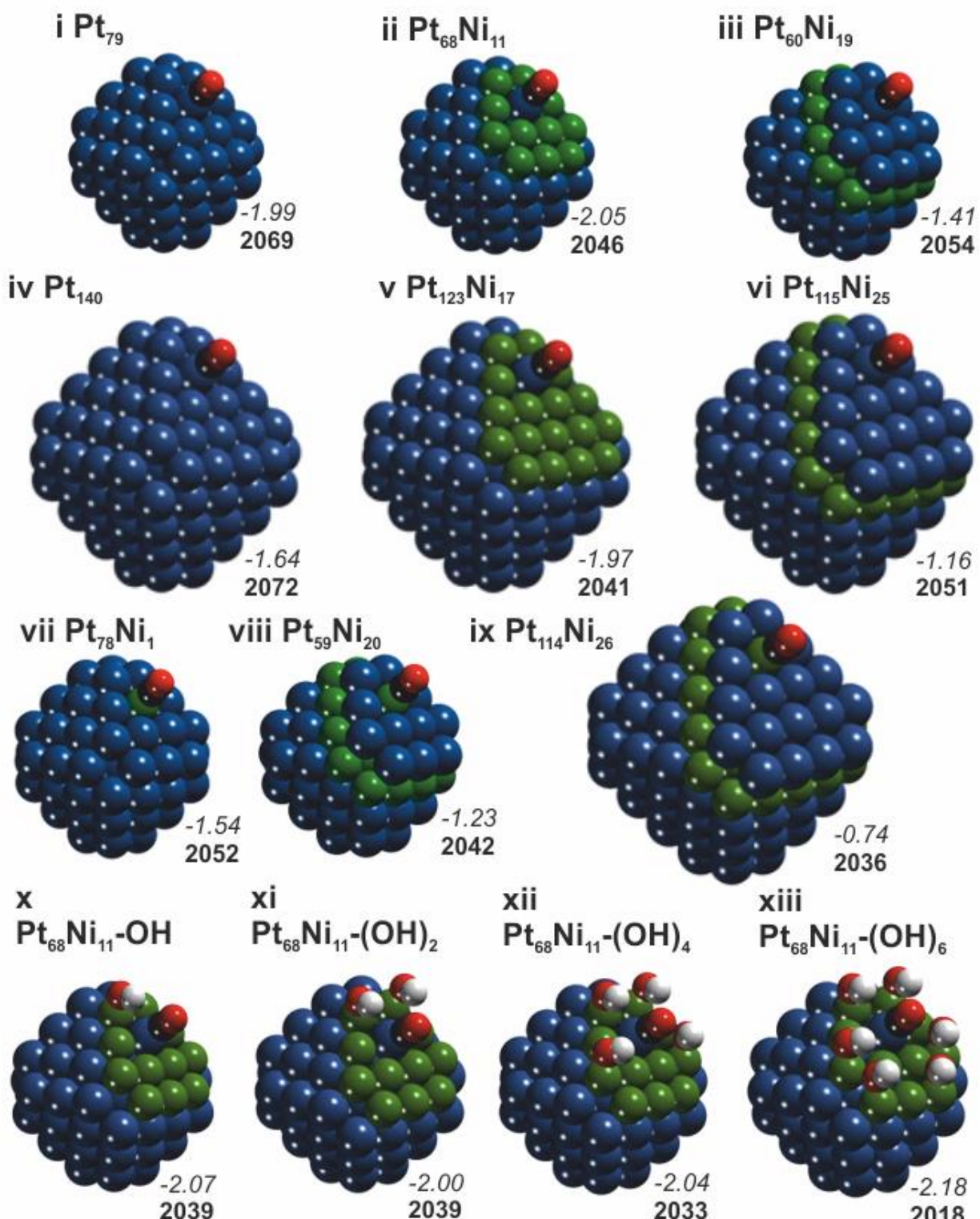

$\mathrm{xi}$

2042
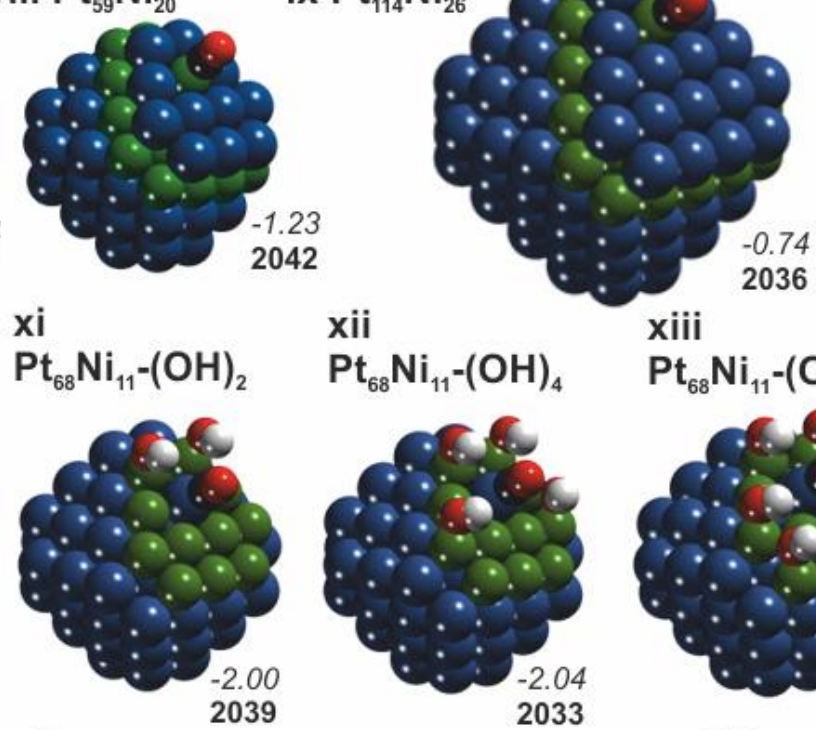

$$
\mathrm{Pt}_{68} \mathrm{Ni}_{11}(\mathrm{OH})_{6}
$$
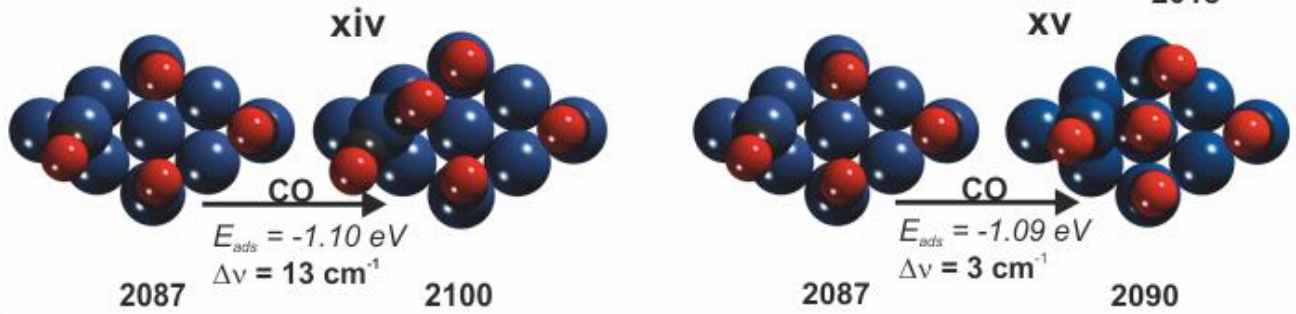

Figure 7: Overview over the Pt and PtNi nanoparticle and slab models used in the DFT studies. For each model, $\mathrm{CO}$ adsorption energies (italic numbers in $\mathrm{eV}$ ) and stretching frequencies (bold numbers in $\mathrm{cm}^{-1}$ ) are given. Atom colors: $\mathrm{Pt}$ - blue, $\mathrm{Ni}$ - green, $\mathrm{C}$ - black, $\mathrm{O}-$ red, $\mathrm{H}-$ gray. See text for discussion. 


\section{Literature}

[1] a) M. Shao, Q. Chang, J.-P. Dodelet, R. Chenitz, Chemical reviews 2016, 116, 3594-3657; b) S. M. M. Ehteshami, S. H. Chan, Energy Policy 2014, 73, 103-109.

[2] a) I. Katsounaros, S. Cherevko, A. R. Zeradjanin, K. J. J. Mayrhofer, Angewandte Chemie International Edition 2014, 53, 102-121; b) H. A. Gasteiger, S. S. Kocha, B. Sompalli, F. T. Wagner, Applied Catalysis B: Environmental 2005, 56, 9-35.

[3] a) V. R. Stamenkovic, B. Fowler, B. S. Mun, G. Wang, P. N. Ross, C. A. Lucas, N. M. Markovic, Science 2007; b) S. Mukerjee, S. Srinivasan, Journal of Electroanalytical Chemistry 1993, 357, 201-224; c) S. Mukerjee, J. McBreen, Journal of Electroanalytical Chemistry 1998, 448, 163-171.

[4] M. Pourbaix, Atlas of electrochemical equilibria in aqueous solutions, Pergamon Press, Oxford; New York, 1966.

[5] a) T. Toda, H. Igarashi, H. Uchida, M. Watanabe, Journal of The Electrochemical Society 1999, 146, 3750-3756; b) V. R. Stamenkovic, B. S. Mun, K. J. J. Mayrhofer, P. N. Ross, N. M. Markovic, Journal of the American Chemical Society 2006, 128, 8813-8819.

[6] a) V. Stamenkovic, B. S. Mun, K. J. J. Mayrhofer, P. N. Ross, N. M. Markovic, J. Rossmeisl, J. Greeley, J. K. Nørskov, Angewandte Chemie 2006, 118, 2963-2967; b) I. E. Stephens, A. S. Bondarenko, U. Grønbjerg, J. Rossmeisl, I. Chorkendorff, Energy \& Environmental Science 2012, 5, 6744-6762.

[7] W. Yu, M. D. Porosoff, J. G. Chen, Chemical Reviews 2012, 112, 5780-5817.

[8] a) P. Strasser, S. Koh, T. Anniyev, J. Greeley, K. More, C. Yu, Z. Liu, S. Kaya, D. Nordlund, H. Ogasawara, M. F. Toney, A. Nilsson, Nature Chemistry 2010, 2, 454-460; b) P. C. Jennings, H. A. Aleksandrov, K. M. Neyman, R. L. Johnston, Nanoscale 2014, 6, 1153-1165; c) P. C. Jennings, H. A. Aleksandrov, K. M. Neyman, R. L. Johnston, Physical Chemistry Chemical Physics 2014, 16, 26539 26545; d) P. C. Jennings, H. A. Aleksandrov, K. M. Neyman, R. L. Johnston, The Journal of Physical Chemistry C 2015, 119, 11031-11041.

[9] P. P. Edwards, V. L. Kuznetsov, W. I. David, N. P. Brandon, Energy policy 2008, 36, 4356-4362.

[10] A. A. Topalov, I. Katsounaros, M. Auinger, S. Cherevko, J. C. Meier, S. O. Klemm, K. J. J. Mayrhofer, Angewandte Chemie International Edition 2012, 51, 12613-12615.

[11] a) A. A. Topalov, S. Cherevko, A. R. Zeradjanin, J. C. Meier, I. Katsounaros, K. J. Mayrhofer, Chemical Science 2014, 5, 631-638; b) S. Cherevko, A. R. Zeradjanin, G. P. Keeley, K. J. J. Mayrhofer, Journal of The Electrochemical Society 2014, 161, H822-H830; c) S. Cherevko, A. A. Topalov, A. R. Zeradjanin, G. P. Keeley, K. J. J. Mayrhofer, Electrocatalysis 2014, 5, 235-240.

[12] a) Y. Shao-Horn, W. C. Sheng, S. Chen, P. J. Ferreira, E. F. Holby, D. Morgan, Top Catal 2007, 46, 285-305; b) P. J. Ferreira, G. J. la O', Y. Shao-Horn, D. Morgan, R. Makharia, S. Kocha, H. A. Gasteiger, Journal of The Electrochemical Society 2005, 152, A2256-A2271; c) R. Borup, J. Meyers, B. Pivovar, Y. S. Kim, R. Mukundan, N. Garland, D. Myers, M. Wilson, F. Garzon, D. Wood, P. Zelenay, K. More, K. Stroh, T. Zawodzinski, J. Boncella, J. E. McGrath, M. Inaba, K. Miyatake, M. Hori, K. Ota, Z. Ogumi, S. Miyata, A. Nishikata, Z. Siroma, Y. Uchimoto, K. Yasuda, K.-i. Kimijima, N. Iwashita, Chemical Reviews 2007, 107, 3904-3951; d) M. Inaba, ECS Transactions 2009, 25, 573 581.

[13] a) K. Schlögl, K. J. J. Mayrhofer, M. Hanzlik, M. Arenz, Journal of Electroanalytical Chemistry 2011, 662, 355-360; b) L. Castanheira, W. O. Silva, F. H. B. Lima, A. Crisci, L. Dubau, F. Maillard, Acs Catalysis 2015, 5, 2184-2194.

[14] a) P. B. Balbuena, R. Callejas-Tovar, P. Hirunsit, J. M. Martínez de la Hoz, Y. Ma, G. E. RamírezCaballero, Topics in Catalysis 2012, 55, 322-335; b) K. J. J. Mayrhofer, K. Hartl, V. Juhart, M. Arenz, Journal of the American Chemical Society 2009, 131, 16348-16349.

[15] J. Erlebacher, M. J. Aziz, A. Karma, N. Dimitrov, K. Sieradzki, Nature 2001, 410, 450-453. 
[16] a) M. Vorokhta, I. Khalakhan, I. Matolínová, M. Kobata, H. Yoshikawa, K. Kobayashi, V. Matolín, Applied Surface Science 2013, 267, 119-123; b) V. Matolín, I. Matolínová, M. Vaclavu, I. Khalakhan, M. Vorokhta, R. Fiala, I. Pis, Z. Sofer, J. Poltierová-Vejpravová, T. Mori, Langmuir 2010, 26, 1282412831.

[17] a) I. Khalakhan, M. Vorokhta, M. Václavů, B. Šmíd, J. Lavková, I. Matolínová, R. Fiala, N. Tsud, T. Skála, V. Matolín, Electrochimica Acta 2016, 211, 52-58; b) M. Vorokhta, I. Khalakhan, M. Václavů, G. Kovács, S. M. Kozlov, P. Kúš, T. Skála, N. Tsud, J. Lavková, V. Potin, I. Matolínová, K. M. Neyman, V. Matolín, Applied Surface Science 2016, 365, 245-251; c) R. Fiala, M. Vaclavu, M. Vorokhta, I. Khalakhan, J. Lavkova, V. Potin, I. Matolinova, V. Matolin, Journal of Power Sources 2015, 273, 105109.

[18] A. Rabis, P. Rodriguez, T. J. Schmidt, ACS Catalysis 2012, 2, 864-890.

[19] a) L. A. Kibler, Short Course Held at the 51st and 53rd Annual Metting of the ISE 2003; b) C. Korzeniewski, V. Climent, J. M. Feliu, Electroanalytical chemistry: A series of advances 2011, 24, 75.

[20] G. Kresse, J. Furthmüller, Physical Review B 1996, 54, 11169-11186.

[21] J. P. Perdew, K. Burke, M. Ernzerhof, Physical Review Letters 1996, 77, 3865-3868.

[22] G. Kresse, D. Joubert, Physical Review B 1999, 59, 1758-1775.

[23] M. Methfessel, A. T. Paxton, Physical Review B 1989, 40, 3616-3621.

[24] a) S. M. Kozlov, H. A. Aleksandrov, J. Goniakowski, K. M. Neyman, The Journal of Chemical Physics 2013, 139, 084701; b) F. Viñes, F. Illas, K. M. Neyman, Angewandte Chemie International Edition 2007, 46, 7094-7097.

[25] H. J. Monkhorst, J. D. Pack, Physical Review B 1976, 13, 5188-5192.

[26] O. Brummel, F. Waidhas, F. Faisal, R. Fiala, M. Vorokhta, I. Khalakhan, M. Dubau, A. Figueroba, G. Kovács, H. A. Aleksandrov, G. N. Vayssilov, S. M. Kozlov, K. M. Neyman, V. Matolín, J. Libuda, The Journal of Physical Chemistry C 2016, 120, 19723-19736.

[27] a) K. Aljaafgolze, D. M. Kolb, D. Scherson, Journal of Electroanalytical Chemistry 1986, 200, 353362; b) A. M. Gómez-Marín, J. Clavilier, J. M. Feliu, Journal of Electroanalytical Chemistry 2013, 688, 360-370.

[28] a) M. T. M. Koper, J. J. Lukkien, Journal of Electroanalytical Chemistry 2000, 485, 161-165; b) A. Berná, V. Climent, J. M. Feliu, Electrochemistry Communications 2007, 9, 2789-2794.

[29] A. M. Gómez-Marín, R. Rizo, J. M. Feliu, Beilstein Journal of Nanotechnology 2013, 4, 956-967.

[30] a) A. Björling, E. Ahlberg, J. M. Feliu, Electrochemistry Communications 2010, 12, 359-361; b) A. Björling, J. M. Feliu, Journal of Electroanalytical Chemistry 2011, 662, 17-24.

[31] A. M. Gómez-Marín, J. M. Feliu, Electrochimica Acta 2012, 82, 558-569.

[32] F. M. Hoffmann, Surface Science Reports 1983, 3, 107-192.

[33] a) N. Lebedeva, M. Koper, E. Herrero, J. Feliu, R. Van Santen, Journal of Electroanalytical Chemistry 2000, 487, 37-44; b) D. S. Strmcnik, D. V. Tripkovic, D. van der Vliet, K.-C. Chang, V. Komanicky, H. You, G. Karapetrov, J. P. Greeley, V. R. Stamenkovic, N. M. Markovic, Journal of the American Chemical Society 2008, 130, 15332-15339; c) N. Hoshi, M. Tanizaki, O. Koga, Y. Hori, Chemical physics letters 2001, 336, 13-18; d) F. Vidal-Iglesias, J. Solla-Gullón, J. Campina, E. Herrero, A. Aldaz, J. Feliu, Electrochimica Acta 2009, 54, 4459-4466; e) A. López-Cudero, A. Cuesta, C. Gutiérrez, Journal of Electroanalytical Chemistry 2005, 579, 1-12; f) S. C. S. Lai, N. P. Lebedeva, T. H. M. Housmans, M. T. M. Koper, Top Catal 2007, 46, 320-333; g) T. Iwasita, G. Camara, Elsevier Science BV: Amsterdam, 2007, pp. 33-61; h) B. Beden, C. Lamy, N. R. de Tacconi, A. J. Arvia, Electrochimica Acta 1990, 35, 691-704.

[34] A. Rodes, R. Gómez, J. M. Feliu, M. J. Weaver, Langmuir 2000, 16, 811-816.

[35] H. A. Aleksandrov, K. M. Neyman, K. I. Hadjiivanov, G. N. Vayssilov, Physical Chemistry Chemical Physics 2016, 18, 22108-22121 
[36] a) C. W. Olsen, R. I. Masel, Surface Science 1988, 201, 444-460; b) S. C. Chang, L.-W. H. Leung, M. J. Weaver, The Journal of Physical Chemistry 1989, 93, 5341-5345. 